\title{
In the Shadows of the Himalayan Mountains: Persistent Gender and Social Exclusion in Development
}

\author{
Coordinating Lead Authors \\ Bernadette P. Resurrección, Stockholm Environment Institute, Bangkok, Thailand, \\ e-mail: bernadette.resurreccion@sei.org \\ Chanda Gurung Goodrich, International Centre for Integrated Mountain Development, Kathmandu, Nepal, \\ e-mail: Chanda.Goodrich@icimod.org (corresponding author) \\ Yiching Song, Centre for Chinese Agricultural Policy (CCAP), Chinese Academy for Science, Beijing, China, \\ e-mail: songyc.ccap@igsnrr.ac.cn
}

\section{Lead Authors}

Aditya Bastola, South Asia Consortium for Interdisciplinary Water Resources Studies (SaciWATERs), Hyderabad, India, and International Centre for Integrated Mountain Development, Kathmandu, Nepal, e-mail: Aditya.Bastola@icimod.org

Anjal Prakash, International Centre for Integrated Mountain Development, Kathmandu, Nepal, e-mail: Anjal.Prakash@icimod.org

Deepa Joshi, Centre for Agroecology, Water and Resilience (CAWR), Coventry University, e-mail: deepa.joshi@coventry.ac.uk

Janwillem Liebrand, Water Resources Management Group, Wageningen University, Wageningen, The Netherlands, e-mail: janwillem.liebrand@wur.nl

Shaheen Ashraf Shah, USAID-funded Pakistan Reading Project (PRP), Islamabad, Pakistan,

e-mail: shani.ashraf9@gmail.com

\section{Review Editor}

Sara Ahmed, Centre for Heritage Management, Ahmedabad University, India, e-mail: sara.ahmed@ahduni.edu.in

\section{Corresponding Author}

Chanda Gurung Goodrich, International Centre for Integrated Mountain Development, Kathmandu, Nepal, e-mail: Chanda.Goodrich@icimod.org 


\section{Contents}

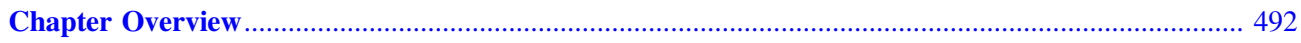

14.1 Context and Particularities to Gender and Social Inclusion in the HKH ............................. 495

14.2 Climate Change and Gender: Experiences from Below …................................................. 496

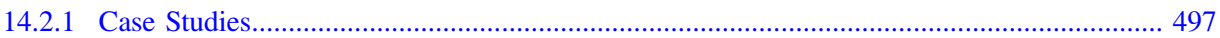

14.2.2 Social Structure, Gender, and Climate Change: Differential Vulnerabilities....................... 503

14.3 Environmental Governance and Gender in the HKH: A Cautious View on Green Growth

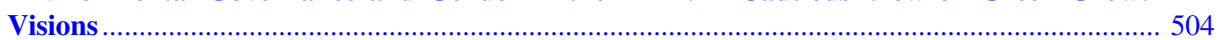

14.3.1 Gender Mainstreaming Policies and Institutions ................................................................ 505

14.3.2 How Policies for Gender Mainstreaming and Social Inclusion Unfold on the Ground....... 506

14.3.3 Professionals, Knowledge, and Masculinities: A Scale Challenge in NRM Governance.... 510

14.4 Conclusion

\section{Chapter Overview}

\section{Key Findings}

1. Polices and responses in HKH countries overlook women's multiple forms of oppressions and exclusions. Since women and men in the region are a heterogeneous group, they have overlapping ethnic, class, and caste identities that result in multiple forms of marginalization and exclusion. However, too many simplifications and one-dimensional framings around women's identities - and people - persist, and policies and responses end up overlooking multiple forms of oppression and exclusions.

2. Existing laws and policies do not support the multiple ways in which women negotiate their roles in households, communities, and the market. This is because men from the mountain regions are out-migrating in large numbers leaving women to manage not just household work but also other work related to agriculture, natural resource management, community and even other public sphere related work - markets or public institutions - that were traditionally men's role. As an example, land tenure and employment policies undervalue rural women's critical roles in food security, sustainable agriculture, and natural resource management despite women taking on the major role in these sectors.

3. Women throughout the HKH do not have corresponding decision-making rights or control over resources despite shouldering both productive and reproductive workloads and responsibilities. This results in undervaluation of their work in society and therefore not taken into account in most policy making processes and outcomes.

\section{Policy Messages}

1. Policies that support adaptation to climate change will not succeed unless they consider gender and how it interacts with other factors such as class/caste, ethnicity, and geography, which will require disaggregated data. The available national data on women in HKH countries does not reflect the diversity and intersectionality, because they rely on aggregate measurements and aggregated country data that may not be representative of the mountain areas. It is critical that disaggregated mountain specific data be collected and analysed to inform policies that are suitable.

2. Policies to improve women's participation in decision making and climate governance must go beyond numbers and quotas to create mechanisms that ensure empowerment and promote women's rights and agency. Given the fragile and dispersed nature of settlements in the $\mathrm{HKH}$, facilitating women's active voice and 
agency will equally require working with gender responsive grassroots organizations and nurturing local and inclusive leadership, (i.e. top-down and bottom up approaches).

3. All levels of government must allocate resources - financial and human-for gender responsive interventions at scale and adopt clear accountability mechanisms, such as gender budgeting, to demonstrate their commitment to gender equality as indicated in the SDGs. Most countries in the HKH lack gender budgeting and accountability mechanisms on gender-almost all government agencies are male-dominated and gender neutral.

Climate change and extreme weather events in combination with socioeconomic processes and opportunities have an especially severe impact on people living in remote mountain areas of the Hindu Kush Himalaya (HKH). For instance, growing urbanisation of mountain towns and cities and globalisation has led to aspirations and consumerism, which is a significant push factor in migration. At the same time, unreliable rural and agricultural outcomes are seen as increasing outmigration of men seeking better livelihoods for their families. This situation can leave women with heavier work burdens, but might also provide women with a complex, newfound 'independence' (well-established).

This shift in women's and men's responsibilities has not been matched by a corresponding shift in policies and attitudes about gender. For example, policies on land tenure and employment disadvantage rural women and men - especially those in poor remote mountainous areas - by undervaluing their critical roles in food security, sustainable agriculture, and natural resource management (established but incomplete).

Furthermore, even as gender inequalities develop in an increasingly complex manner with contextual political and economic situations intersecting with class, caste, religion, age, and ethnicity, there are continued assumptions made around a single homogenous class of 'mountain' women.

Although less is known about the gender-differentiated effects of climate change, particularly in the context of limited economic opportunities in mountain areas, studies illuminate the relative quality of women's and men's lives, livelihoods, and access to resources under equally changing socioeconomic and political conditions (established but incomplete).

The linear, techno-managerial approaches to climate governance with simplistic one-size-fits-all solutions and 'quick fixes' for gender equality and women's empowerment fail to recognize the complexity of women's and men's realities (established but incomplete).

\section{Problematic understanding of gender}

Most often, understandings of gender are simplistic: Gender is equated with women, particularly poor rural women. Notions of gender are simplified in policy making, and reduced to the inclusion of some "poor women". This simplistic and apolitical interpretation and way of integrating gender into climate interventions and policies poses large problems, which manifests in the assumption that engaging women on projects is taking care of women's needs and will lead to women's empowerment (well-established).

Furthermore, there is the paradoxical positioning of homogenous categories of "mountain women" as being both "vulnerable victims" of climate change as well as "formidable champions" of climate adaptation. This has led to extreme approaches in policies: from a welfare approach in which women are taken as passive beneficiaries to one where they are seen as "fixers" of environmental problems based on assumptions about their "volunteer" time in projects as "natural care-givers" (well-established).

This dichotomization of women into one of two identifiers creates policymaking foci on numbers and quotas as measures of change and progress, rather than on the structural issues of inequality and discrimination. A major problem is the overlooking of gender relations between women and men, between women, and between men (wellestablished).

Related to the above is the focus on numbers and quotas as measures of change and progress, rather than on the structural issues of inequality and discrimination. A major problem is the overlooking of gender relations between women and men, between women, and between men (wellestablished).

The empirical problem: How data aggregation obscures women's complex experiences in the HKH?

Gender differences intersect with other dimensions of social and geographical differentiation. Class, caste, ethnicity, and age intersect with different geographical and sociocultural settings such as upstream, midstream, and downstream communities in mountain contexts to produce differential access to resources. Women and men are thus marked by multiple, coexisting identities that create overlapping - and often conflicting-relations of inequality and hierarchy, inclusion and exclusion.

However, the available national data on women in $\mathrm{HKH}$ countries does not reflect this diversity and intersectionality, because they rely on aggregate measurements. Part of the problem is that aggregated country data may not be representative of the mountain areas, which (except in Bhutan and Nepal) form only a portion of $\mathrm{HKH}$ countries' national 
territories. This lack of mountain specificity could help to explain, for example, why the 2014 Gender Inequality Index ${ }^{1}$ varies so widely across the $\mathrm{HKH}$, from China with the lowest inequality to Afghanistan with the highest (established but incomplete).

Questions about interventions: How to engage women and men of disadvantaged groups?

Policies and programs have long focused on the functional rather than the structural aspects of gender relations. In most sectors, gender mainstreaming policies have applied the concept of gender narrowly, often as a synonym for "poor [rural] women"-and without further differentiation of these women's needs, interests, emotions, identities, and roles. As a result, these policies produce technocratic quick fixes that place unrealistic burdens on women already in poverty (wellestablished).

To be sure, today's technocratic programs include women in economic development. Yet this inclusion is rationalized only by an appeal to economic gain. While the pursuit of economic efficiency can offer women economic opportunities, it does not fully address their unequal power relations with men, vis-à-vis equal wages for equal work, or the sharing of domestic work responsibilities (established but incomplete).

\section{Exploring 'feminisation of responsibilities' and addressing a masculine working culture}

As more men migrate in search of livelihood options, rural women assume a disproportionate share of responsibilitiesagricultural labour, reproductive work, and other labour that supports community welfare, as well as responsibilities in the public sphere, giving rise to a gendered rhetoric of 'feminisation of responsibilities'. Within this women may be assigned new 'caring' roles as 'climate agents', expected to adapt to climate change and cushion its adverse effects on their households and communities. Such rhetoric has the effect of adding climate change adaptation to the list - already long _ of women's caring roles (established but incomplete).

As important as it is to analyse the rhetoric of women's roles, what is considered or played out as roles for and by men - and the nature of these gendered divisions of labour and how these vary across socio-political and socio-ecological contexts-requires attention, especially at the science and policy levels. Yet, there is often little attention to these, and assumptions are made, especially of

\footnotetext{
${ }^{1} \mathrm{GII}$ is an index developed by UNDP that measures gender inequality on three counts - health, empowerment and participation in labour markets (UNDP 1995).
}

what women [can do] and do in policy and practice. It is important to add here that since men continue to be key actors in environmental science, policy, and intervention across South Asia, the manner in which masculinity mediates environmental science, policy, and governance is important to know and address. Progressive policies in irrigation and water planning, for example, will require that we address the 'masculine' working culture in this sector. Often, engineers and experts adhere to a hegemonic culture of science and technology, upholding 'masculine' professional norms ensures credibility - and yet, paradoxically, these same professionals may be the ones tasked with formulating and implementing policies that promote diversity, gender equality, and social inclusion (established but incomplete).

\section{Gender, Inclusive Development and the Sus- tainable Development Goals}

The SDGs are broader than the MDGs as they include environmental, social, and economic sustainability, and are also "potentially more transformative" better reflecting complex challenges and the need for structural reform (Sakiko 2016, p. 47). Sakiko further points out that the gender-specific SDG 5-“Achieve gender equality and empower all women and girls" has multidimensional implications that integrate targets "related to gender-based violence, harmful practices, unpaid care work, voice, sexual and reproductive health and rights, economic resources, technology, and legislative change". Furthermore, gender issues and targets are not limited to SDG 5 only but are also reflected in other goals, such as those related to poverty, hunger, education and health, water and sanitation, and work.

The underlying transformative agenda and incorporation of the complex and multifaceted realities of women's lives in the SDGs are all the more relevant to the HKH, where social and gender inequalities persist such as groups of women in mountain areas who perform multiple roles: in the household, agriculture, natural resource management, communities, and the markets and other public spaces at higher scales, and particularly with the trend of large-scale male outmigration.

Consequently the nine $\mathrm{HKH}$ priorities clearly envision sustainable development of the region and its peoples with a transformative agenda of equity and inclusion. Priority 3-“Achieve gender and social equity through inclusive and transformative change in the mountains"--links directly with SDG 5 and goes a step ahead in its transformative agenda as the targets address the many facets of the complex realities of women's lives-gender-based violence, participation in decision making, gender equality and disparity, and 
practices of social and gender exclusions, policies, and institutions. Priority 3, while being a standalone goal, also links with all the other priorities as each priority has social and gender dimensions as well as targets, which has further implications for gender equality and transformative change. The need of the hour is for development actors and policy makers to integrate gender and social inclusion targets and indicators in all actions and policies.

This new transformative agenda points out the need to do much more than the usual rhetoric on gender and unravel the complex and interrelated dimensions of women's and men's lives.

\subsection{Context and Particularities to Gender and Social Inclusion in the HKH}

The Hindu Kush Himalaya (HKH) are considered one of the most ecologically sensitive areas in the world. Although data is limited and contested, it is generally agreed that the effects of climate change are predicted to happen here "first" and with the greatest intensity (Singh et al. 2011, p. iv). What is less well known is how the effects of climate change will impact the geographically diverse mountain ecosystems and, in turn, the lives, livelihoods, and resources of diverse communities in the region.

In this chapter we draw attention to the fact that climate change problems and solutions are largely techno-centric in design. Jasanoff (2010) notes that "modern science" has framed climate change as a global phenomenon that "detaches knowledge from meaning". Technical observations of more easily measurable phenomena such as changes in temperature and precipitation undermine attention to the understanding of the embedded local experiences of people as well as "social institutions and ethical commitments at four levels: communal, political, spatial and temporal" (Jasanoff 2010, p. 233). In other words, little is known about how changes in climate will result in complex changes in the quality of lives, livelihoods, and resources of diverse groups of people. We argue that, especially in the $\mathrm{HKH}$, it is important and necessary to creatively link "abstract generalizations, specificity and objectivity" of climate science and climate interventions with contextually relevant "scales of social meanings", experiences, and subjectivities (Jasanoff 2010, p. 235). Similar concerns were echoed by Forsyth (2001), who questions how far the so-called scientific descriptions of environmental change have been accepted as factual without this being reflected by the experiences and values of marginalised people.
In this chapter, we focus on unpacking popular assumptions related to climate change and proposed climate interventions using a social relations approach (SRA) and feminist political ecology (FPE) framework. For this work, we provide case studies that demonstrate the complex workings of gender relations in the context of climate change in the HKH. Specifically, these case studies highlight the unique, embodied experiences of climate change and how gender power relations affect green economy interventions.

\section{Box 14.1 What is gender?}

Gender refers to socially constructed roles, responsibilities, and opportunities associated with men and women, as well as hidden power structures that govern the relationships between them. Inequality between the sexes is not due to biological factors, but is determined by the learnt, unequal, and inequitable treatment socially accorded to women (UNDP 2010).

As social differentiations and identities based on class, caste, ethnicity, age, and other factors intersect with gender, addressing gender requires understanding that women [as well as men] are not homogeneous categories.

This chapter aims to critically assess two primary issues:

- The intersections between gender and social equity with climate change in the context of changing realities across the HKH

- How climate-related institutional interventions respond - or do not respond - to the complex and diverse realities of people's lives on the ground.

In this assessment we combine the SRA and FPE approaches (Box 14.2).

\section{Box 14.2 Social relations approach and feminist} political ecology frameworks

The Social Relations Approach (SRA) focuses on the nature and construct of inequality as determined through distributions of resources, responsibilities, and power. It emphasizes the analysis of relationships between people, their relationship to resources and activities, and how these are reworked across institutional levels in specific contexts-from the household to formal and informal institutions including the state and the market. SRA also emphasizes the idea that the overall goal of development interventions is and should be human wellbeing and not just economic growth (Kabeer 1994; Kabeer and Subrahmanian 
1996, p. 25). Thus the social relations approach departs from narrow, technical interpretations of gender as women and of women and men as isolated categories, thus shifting away from the rather "impersonal, apolitical, and universal imaginary of climate change [impacts and interventions], projected and endorsed by science" (Jasanoff 2010, p. 235).

Feminist political ecology (FPE) recognises the close interlinkages of gender with other social categories and differences in gender-environment relations, and points out that resource-related relationships relate to "women's particular circumstances" (Molyneux 2007, p. 231). These circumstances not only interact with class, caste, race, culture, and ethnicity to shape processes of ecological change; they also differ in different social, political, and economic settings dynamically shaping "gender as a critical variable in shaping resource access and control" (Rocheleau et al. 1996, p. 4). FPE recognizes the importance of conducting 'science from below' or examining people's embodied experiences of resource degradation, disasters, mobility, and displacement as these connect with other scales of power and decision making (Hanson 2015; Harding 2008). In short, feminist political ecology is concerned with an intersectional analysis on gender-environment relations that actively considers gender in combination with social factors such as race, ethnicity, caste, class, age, disability, and others.

There are thus several similarities between the SRA and FPE frameworks in their aim to capture the complexity of gender-power relations, to unpack the gendered nature of institutions at scale, and to map the interactions between policies, practices, and ground realities at different institutional locations (Hillenbrand et al. 2014).

Mountain peoples, characterised by socio-ecological differences, have a crucial role in natural resource management and climate change adaptation. To evolve a more contextualised understanding of the $\mathrm{HKH}$, it is important to examine the drivers of change behind gendered lives and livelihoods, as gender relations vary in complex ways. Overall the livelihoods of mountain communities in the HKH are largely agrarian: agriculture, livestock, and management of natural resources. Coping strategies in response to themyriad drivers of change include migration, wage and casual labour, and labour-intensive household management and income generation through small-scale trade (Leduc 2009). Natural resource management also figures heavily into community-based and individual/household coping strategies, drawing from a rich traditional culture and knowledge about this topic.
The processes of globalisation, regionalisation, and economic liberalisation are connecting markets and reconfiguring economic relations, interactions, and dependencies. While global birth rates are levelling, population continues to grow rapidly in the $\mathrm{HKH}$, placing additional pressure on urban environments and infrastructure in contexts in which government policies alone are unable to curb the trends (Karki et al. 2011; UN-HABITAT 2007). These trends have also meant opening up mountain communities to a wider world of institutional arrangements, relationships, and opportunities, and the emergence of a consumer class that is shaping new aspirations and desires, sculpted by a culture of money (GoN 2014). In tandem, these trends alter land-human relationships, affecting how people use, access, control, and manage natural resources (Jodha 2007). In this process, local knowledge systems are rendered obsolete while giving rise to new bodies of information, creating new livelihood systems, and setting in motion new patterns of consumption and acquisition, as well as "reconfiguring people's relationships to one another, within and across households and communities ... within and among state institutions and other macro agencies" (Gurung and Bisht 2014, p. 5). Furthermore, rural to urban migrants-largely young men - seek off-farm employment leading to changing demographic patterns, with growing elderly rural populations and the 'feminisation' of farm and non-farm activities in terms of production, exchange, and distribution (also see Chap. 15).

These factors or drivers are affecting women and men differently and changing gender roles and relations, leading to a widening of the differences between women's and men's income-earning and asset-controlling possibilities (Bastola et al. 2015; Nellemann et al. 2011; Nibanupudi and Khadka 2015; Sogani 2013).

\subsection{Climate Change and Gender: Experiences from Below}

Few studies focus on understanding gendered impacts due to changing climate in the HKH (Ogra and Badola 2015). In this context, it is critical to recognize that gender does not equate to women: There is no single class of $\mathrm{HKH}$ women and men, and no universality of experience in regard to climate change impacts. Understanding the complexities of diverse nature-society interrelations in the context of climate change in the $\mathrm{HKH}$ requires a viewpoint from below.

It is widely recognized that, on the one hand, climate change results in higher risks and greater burdens for women, and on the other hand, due to their local knowledge and management of households, women play critical roles in adaptation. Such generalizations are especially prominent in popular discourse on climate and mountain women in the 
Fig. 14.1 Case studies of climate change and genderexperiences from below

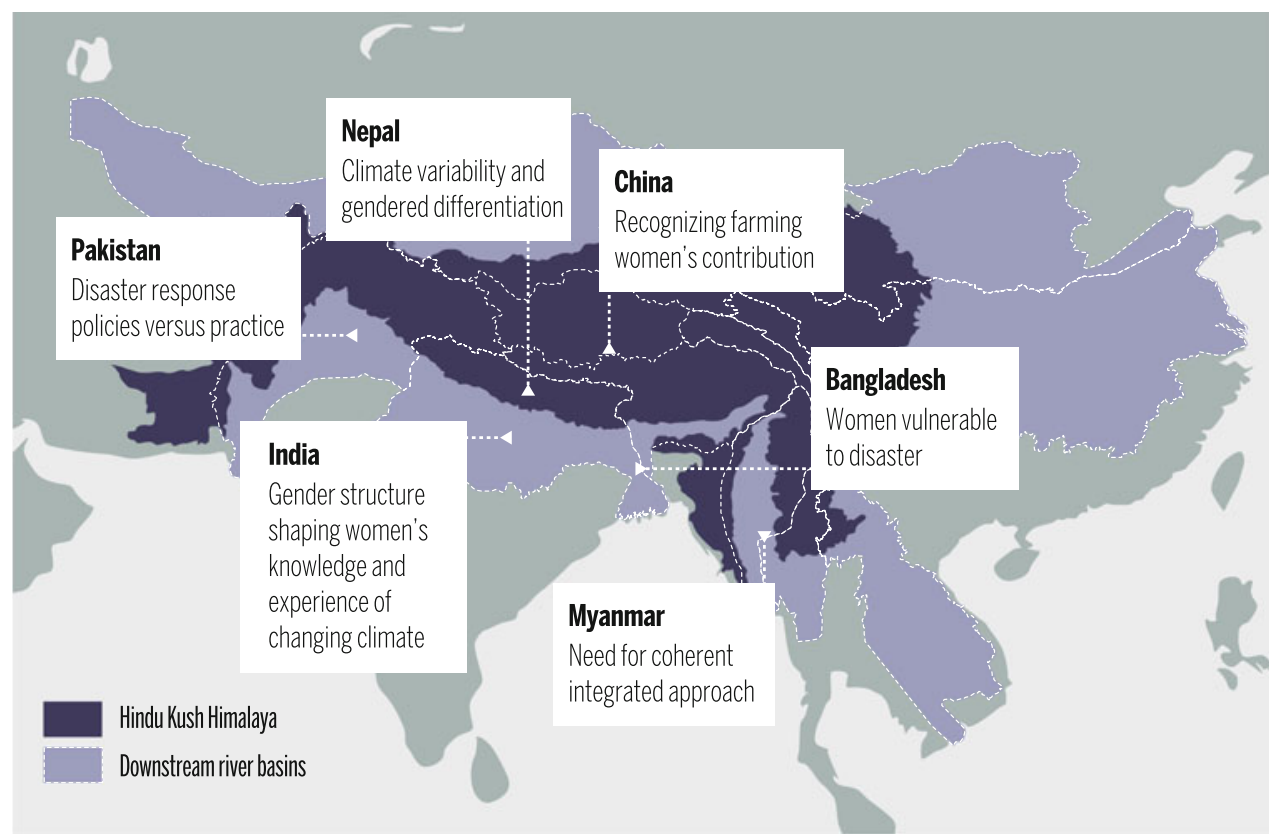

HKH (Joshi 2014, p. 247). There are countless case studies of mountain women who, through their experience, responsibilities, and strength, are reported to play a much stronger role than men in the management of ecosystem services and food security, and therefore in climate change adaptation (Nellemann et al. 2011). Mountain women's knowledge, capability, and commitment to the environment and their families are used to highlight their ability to adapt in extreme situations such as conflict, natural disasters, and displacement (Leduc 2010). Such narratives create persuasive arguments that mountain women are critical actors in mitigating and adapting to climate change. But what is also important to consider is that despite the criticality of their roles, women in the $\mathrm{HKH}$ face challenging situations and obstacles as they carry out these roles.

This section of the chapter focuses on how gender and other social relations are negotiated with increasing climate variability. Within similar geographical regions, cultures, ethnicities, castes, and ecological settings, discriminative practices are likely to intensify with increasing environmental change (Bhattarai et al. 2015). In this context, we explore gender-differentiated access and control over resources and its impact on women and men in the $\mathrm{HKH}$ (Carvajal-Escobar et al. 2008).

\subsubsection{Case Studies}

This subsection problematizes the interplay of gender and other social differences that are superimposed on climate change impacts and create multiple vulnerabilities for the poor and marginalised women and men. Due to a lack of large-scale data, and a lack of cases from all HKH countries, we focus on illustrative case studies to show the interlinkages between gender and climate change. Some specific case studies presented from India, Nepal, Pakistan, Bangladesh, Myanmar, and China highlight the manifestation of gender vulnerability and women's roles from the HKH (see Fig. 14.1).

\subsubsection{Bangladesh-Women Vulnerable to Disaster}

The case of Bangladesh demonstrates how water-related hazards interact with gender to create situations where men and women differently experience, suffer, and cope with hazards and disasters (Sultana 2010). Women are feared to be more vulnerable to climate-induced water-related stresses and extreme events like floods (Brody et al. 2008; Dankelman 2008), and there is ample evidence that during natural disasters women and girls are more prone to mortality compared to men and boys. In Bangladesh, the 1991 cyclones and floods claimed more female lives than male: Amongst females 10 and older, girls and women were three times more likely to have perished (Bern et al. 1993; Parikh 2007; Roehr 2007; Twigg 2004;). In contrast, the mortality rate of men in both flood- and salinity-prone areas was only $17 \%$ of the total (Golam et al. 2009). This higher female death rate has been attributed to gender norms on what men or women should do in a disaster or the resources they have at their disposal (Chowdhury et al. 1993; Dasgupta et al. 2010; Nelson et al. 2002; Neumayer and Plümper 2007; Sharmin and Islam 2013; WEDO 2008).

For example, early warning signals had not reached large numbers of women because the information had been 
disseminated primarily in public places to which many women do not have easy access; and even when women received warnings they were constrained by cultural norms that restrict women's freedom of movement in public - that is, women were not allowed to leave their houses without a male relative, and many women waited for their husbands to return home to take the decision to evacuate, thereby losing precious time that might have saved their lives and those of their children (D'Cunha 1997; Fordham 2001; Mehta 2007; Parikh 2007; Sharmin and Islam 2013; UNEP 1997). Furthermore, conditions in cyclone shelters were not suited to women's needs, for example there were no separate toilets for men and women, poor water, and no toiletries like sanitary pads and the shelters were designed in a manner that was insensitive to gender specific needs and cultural values leading to various problems that enhanced the discomfort particularly for menstruating, pregnant, and lactating women (Baden et al. 1994; D’Cunha 1997; Fordham 2001). Similarly, a rapid gender field survey conducted in 2007 on Cyclone Sidr relief efforts found that after the storm, women were vulnerable to harassment, violence, famine, and human trafficking; the study also found that women were less likely to take off clothing, such as their long saris, during floods and these got caught in the floating debris, increasing their chances of drowning (Lauren Khan 2012). Thus, the differences in the gendered divisions of roles and labour, gendered rights, decision making, and women's weak bargaining power within the household result in women facing more suffering — including sexual assault_-before, during, and after each disaster event.

A recent study by the Bangladesh Centre for Advanced Studies (Mallick et al. 2016) found that poor women and their livelihoods are badly affected by heavy rain, landslides, and water logging in Rangamati District in the Chittagong Hill Tracts (CHT). Small-scale agriculture led by women, water sources, and livelihoods of the poor women and men are severely affected by climate variability and extremes like flash flood, landslides, and water logging. These are causing economic hardship, deepening poverty, and increased food insecurity in the region.

Climate-related water stresses and gender inequalities aggravate the situation for women and girls in a number of ways. For example, poor families have been forced to marry off very young girls, resulting in many dropping out of school and others experiencing violence (Alston et al. 2014; Atkinson and Bruce 2015). Khan et al. (2016) and Khan and Kumar (2010) show how peri-urban communities in the coastal city of Khulna are vulnerable to water insecurity because of their exposure to different stressors including urbanisation. Additionally, climate change has led to rising sea levels and, consequently, saline contamination. As a result, pre-eclampsia, eclampsia, and hypertension among pregnant women is reported to have increased due to increasing salinity of drinking water (Khan et al. 2008, 2014).

The authors report that vulnerability of the peri-urban communities in Khulna varies across the sites as well as gender and different social groups within the communities. Prakash (2016) concludes that disaggregating vulnerability with an intersection of class, caste, and gender is important for understanding the complex issues related to climate change and its implications on gender. Lack of data means a lack of understanding and evidence on gendered vulnerabilities.

In Bangladesh, even when there is severe disruption of local freshwater sources following floods, cyclones, and saline intrusion, women are responsible, irrespective of their physical condition, to provide drinking water for their families for which they must walk long distances-sometimes up to 10 kilometres every day over difficult terrain-in search of water, consuming an enormous amount of their time and effort (WEDO 2008). After floods, day-to-day tasks such as cooking and cleaning the house become more time-consuming due to rising water levels. Women are often compelled to raise their stoves or go to neighbours' houses to prepare food (World Bank 2010). When the flood waters are particularly high, women go out on shallow-bottomed boats some distance to find the privacy to relieve themselves. Lack of supplies, the impossibility of disposal, and the problems of keeping oneself clean make menstruation particularly challenging. For many, the trauma of past experiences with the spate of water-borne diseases continues to linger long after the event (Mehta 2007).

\subsubsection{China-Recognizing Farming Women's Contributions}

China's rapid industrialization, urbanisation, and marketization since the 1980s has meant farmers cannot survive on farming alone due to small average landholdings (0.6 ha). Therefore, many have adapted their coping strategies. For example, the "one household, two sectors" approach (husband in the city, wife on the farm) is common to many families. In this situation, rural women have come to assume greater responsibility for agricultural production on top of their domestic and childcare duties. This is especially true in the poorer remote mountain areas in southwest China, which has a rich agricultural biodiversity that lends itself to using bio-culture farming systems as an adaptation strategy to support rural livelihoods and strengthen food security for the region.

Research carried out by the Centre for Chinese Agriculture Policy (Song et al. 2016) of the Chinese Academy of Sciences revealed that globalisation, rapid development, and climate change had delivered serious impacts to local food systems: severe droughts, increased temperature, and extreme weather. As a result, local farming species and 
Table 14.1 Migrants in total labour force and women migrants in Guangxi and Yunnan

\begin{tabular}{l|l|l|l}
\hline Year & 2002 & 2007 & 2012 \\
\hline \% migrants in total labour force & 42.56 & 55.94 & 62.09 \\
\hline \% women out of total migrants & 38.48 & 39.84 & 42.06
\end{tabular}

Data source Survey of 320 rural households in Guangxi and Yunnan Provinces in 2013 (Song et al. 2016)

landraces were disappearing at an alarming rate, and the existing bio-culture landscape and local seed systems were threatened. These developments have precipitated a rise in social challenges such as extreme poverty, food security issues, increasing environmental degradation, and more frequent natural disasters to small farmers (primarily ethnic women) in remote mountainous areas. Women, as the main cultivators, seed savers, and users, are the most affected by climate changes and at the same time are the key custodians for farmer seeds.

Two village case studies from the rural areas in Guangxi and Yunnan Provinces illustrate some of the challenges facing mountain households. Situated in southwest China, Guangxi and Yunnan are home to most of China's rural poor mountain ethnic minority communities and have a rising trend of male migration. Over the past decade, the percentage of migrants in the total labour force in the communities has grown from $42.56 \%$ (2002) to $62.09 \%$ (2012)-a $20 \%$ increase (Table 14.1). Men comprise the majority of migrants, though many young women migrate as well.

Research shows that women are playing a key role in enhancing agricultural production for their households when offered the opportunity to make important decisions about the farm. In order to help farmers in remote mountain villages conserve seeds, improve their preferred landraces, and redirect benefits, the CCAP team initiated community-based conservation, participatory variety selection trials, and seed production in a number of trial villages in Guangxi and Yunnan through woman farmer-to-woman farmer exchanges facilitated by the project team. This initiative led to increased income and food quality for households participating in the programme (Song et al. 2016).

The participatory plant breeding activities continue today in the villages and to date have conserved more than 100 food crop varieties, improved 15 drought-resistant or quality landraces, and generated significant value for the women's group from seed production and other value-adding activities. A women's group in Guzhai village has developed into women-led farmer cooperatives in 10 years. A women's group in a Yunnan village created an idea exchange with the women's cooperative in Guangxi for learning organic farming. These activities have increased women's income three times more than "modern" agriculture promoted in the last 30 years. More significantly, the process has enhanced women's community-based collaboration in sharing productive activities, managing natural resources, and linking to external information, markets and society. This is quite helpful for empowering women and their self-organization economically and socially (Song and Vernooy 2010; Song et al. 2016).

\subsubsection{India-Gender Structures Shaping Women's Knowledge and Experience of Changing Climate}

Drawing on evidence from four case studies across the Indian Himalaya, this case assesses how gendered institutions shape women's knowledge, experience, and adaptation in changing climatic contexts. In the western Himalayan state of Uttarakhand, Moitra and Kumar (2016) explore the role of community radio in addressing the risks and challenges posed by climate change. Women reported an increase in the intensity of both summer heat and winter cold combined with sustained periods of fog; an increase in the frequency of natural disasters, including drought; and, consequently, more hardships for them in terms of water collection and agriculture. Established in 2000 in the township of Chamba, Garhwal, Henvalvani Community Radio has adopted a variety of broadcasting options combined with innovative activities to create spaces for communities, particularly women, to voice their issues. Engaging scientists in programming on low-cost and accessible solutions to agricultural problems (weeds, pests) for example, has helped women farmers in remote mountain areas sustain their crops and fields.

In their work on Uttarakhand's Nanda Devi Biosphere Reserve, Ogra and Badola (2015) explore the implications of climate change amongst indigenous communities, the Bhotiyas and the Garhwali paharis (mountain folk) whose traditional livelihood strategies based on seasonal migration have given way to agriculture, supplemented by a variety of secondary income-generating opportunities, including eco-tourism. However, while there are increasing opportunities for men as porters and guides, their absence on long treks, for example, poses an additional burden on women's work with limited recognition (Ogra and Badola 2015, p. 513). Impacts on women differ by age and povertyyounger women (daughters-in-law), smaller households, and households without men typically face greater levels of vulnerability reflected in terms of access to food and labour. While economic incentives provided by eco-tourism tend to benefit better-off households that can offer homestay facilities, wider multiplier effects in villages through established social networks have been noted. Additionally, infrastructure improvements at the village and household levels are having positive impacts for women and children, such as improved access to water and sanitation or waste management. Access to information through social interactions with visitors led many women to report an increase in self-awareness and knowledge on conservation and development (Ibid, p. 516). 
Across the Himalaya, in the north-eastern state of Nagaland, Singh and Singh (2015) focus on climate-induced water-stressed communities in four districts: Mon, Mokokchung, Tuensang, and Kohima. The authors explore how climatic factors inducing water stress interact with non-climatic features in this mountainous region, producing new challenges that are gendered in nature. They report that domestic water access has always been a gendered problem, especially during the dry winter months when natural springs and streams dry up or reduce discharge. Women and children are forced to walk long distances downhill in search of water.

Meanwhile, Barua et al. (2014) argue that in Sikkim, vulnerability to climate change is not only about physical or geographical factors, but also structured by socioeconomic factors such as lack of education, health care, and limited livelihood opportunities, which constrain households in overcoming poverty and "weaken their resilience to manage climate risks" (Barua et al. 2014, p. 274). Despite equal opportunities for women in Sikkim in terms of access to employment, education, and health care, deep-rooted gender biases persist. During a crisis, it is the girl child who is withdrawn from the school first and girls are typically discouraged from pursuing higher education if it is at the expense of their domestic responsibilities.

In sum, the case studies show gendered impacts of climate change cut across social differentiated categories that are based on ethnicity and caste. This is particularly true for women from agriculture-dependent households. Furthermore the dimensions that appear crucial for sustainable livelihood development are income, migration status, and household size, as these relate directly to household assets and capacities of the household members. These case studies also reveal that gender division of labour along with gender norms and practices strongly shape women's knowledge and experiences of changing climate. For women in poor families, the hardship is compounded for example they do not have the option of purchasing food, fuelwood, fodder, among others. Thus, the risks and labour costs that women in the study reported as inherent to their work increase in the absence of alternative assets.

\subsubsection{Myanmar-Need for a Coherent and Integrated Approach}

Myanmar is vulnerable to a wide range of hazards including floods, cyclones, earthquakes, landslides, and tsunamis. Over the last decade the country has dealt with the devastating effects of Cyclone Nargis in May 2008, which severely impacted the Ayeyarwady and Yangon Divisions, and Cyclone Giri, which hit Rakhine State in October 2010 (IFRC 2015).

Cyclone Nargis hit Ayeyarwady, killing an estimated 130,000 people, of which $60 \%$ were women (CARE Canada 2010). The impact was immense and led to massive displacement and decimation of agriculture and infrastructure across the region. An estimated 2.4 million people lost their homes and livelihoods: the cyclone caused devastating damage to the environments of Ayeyarwady and Yangon, where local livelihoods are heavily reliant on natural resources (Pender 2009).

In this region, women traditionally play an important role in income generation including small-scale trade, shop keeping, fish processing, and crafts. They also play a key role in subsistence agriculture, fishing activities, and maintaining food security for their households. However, despite these responsibilities, women have less control over resources than men.

Women's Protection Technical Working Group (2010) point out that despite having a range of livelihood opportunities, the overwhelming majority of the people living in areas affected by Cyclone Nargis survive from harvest to harvest, sometimes relying on loans from moneylenders to tide them over to the next season. Of the loans taken out in the region, $50 \%$ go to households that have rights to paddy land, $20 \%$ to households that derive their primary income from fishing, and $30 \%$ to landless labourers. In such a situation, women who survived the cyclone were left more vulnerable — without family, incomes, livelihoods, homes, or assets, and with little access to quality sexual and reproductive health care or psychosocial support services (Women's Protection Technical Working Group 2010).

In the wake of the cyclone, the UN set up the Protection of Children and Women (PCW) cluster under which both children's and women's protection would be addressed (among other protection issues) as autonomous issues, in separate sub-clusters. The Women's Protection technical working group transitioned into a sub-cluster (WPSC), with the focus on multi-sectoral (protection, gender-based violence, livelihoods, education, health, and reproductive health) and cross-cutting (health, psychosocial and legal support) issues faced by women in the context of the cyclone-affected areas (Pender 2009). Pender (2009, p. 4) report states that the main reason for this separate cluster was that the PCW addressed women's issues "only in relation to the relationship of women to children". The report further indicates that the assessments conducted by WPSC show that despite women (particularly young widows, women separated from their families, and single female heads of households) being identified as the most vulnerable by community members, there was lack of targeting the specific needs and experiences of women - for instance, there was little to no gender or age disaggregated data, and there were hardly any stand-alone women's protection programmes. This was largely due to the absence of an overall coordinated structure in the PCW. Consequently, despite the program being community based, it overlooked the women's specific needs and experiences. Furthermore, strategies relating to 
the different sectors such as agriculture and fisheries, were gender blind, and unable to recognising women's contribution in these sectors (such as paddy transplanting and fish processing) (p. 6).

The Pender (2009) report concludes that the formation of the WPSC led to a holistic view, including gender-based violence, whereby the WPSC prioritized the need for holistic support for survivors of gender-based violence, including health, psychosocial, and legal resources. Not only did the program increase the scope of gender-based violence work, but also mainstreamed gender in a practical and tangible way. This contributed to women's empowerment through livelihoods, education, and comprehensive health care services. This is an example of an efficient and coordinated structure that mainstreamed gender across sectors.

A key lesson from this case is that sustainable livelihoods require a coherent and integrated approach across a number of sectors, including water, shelter, livelihoods and food security, education and training, sanitation and hygiene, and disaster risk reduction. Complementing and combining the sectoral approaches with capacity building and institutional strengthening of national and local governments and civil society is critical for the development of laws and policies that support sustainable development (UNEP 2009, 2012).

\subsubsection{Nepal_Climate Variability and Gendered Differentiation}

Bastola et al. (2015) recently conducted a study to understand perceptions of climate change impacts across the mountain, hill, and terai regions in the Central Development Region of Nepal. They posed important questions on how the adverse impacts of a changing environment shaped gender and social relations and added more weight to women's workloads to provide care for family members while also managing the production spheres.

This study illustrates the lack of effort undertaken by intervention agents to understand how climate change differentially impacts women and men, and how little is known about the links between climate change, gender, and other social intersections. This situation is exacerbated by the fact that little gender disaggregated data is available. Moreover, this study supports the findings of other studies (Dhimal 2015; Eriksson et al. 2008; Goh 2012; Leduc et al. 2008; Leduc 2009; Massey et al. 2010) that show how climate variability is more likely to increase women's workloads across sectors. Figure 14.2 shows gender disaggregated agriculture work in the three geographical regions, indicating that women are increasingly involved in agriculture work (such as ploughing, sowing, weeding, irrigating, preparing field channels, harvesting, threshing, and selling of agriculture produce).

The ratio of women to men in agricultural activities is particularly pronounced in the mountain regions, due primarily to male outmigration for work. Gender disaggregated data on work allocation show two major points that have both positive and negative outcomes. On the positive side, women take control on household economic affairs (selling of agriculture produce) that traditionally were controlled by men. On the other side, there is an increasing feminisation of labour where women are forced to bear more responsibility for agriculture activities, particularly in the mountain region where male outmigration is high (Bettini and Gioli 2015). Bhattarai et al. (2015) share similar findings that at least one man from each household in the mountain region has migrated to Gulf Cooperation Council countries or Malaysia.

In cases where both women and men have out-migrated, elderly family members assume the responsibility of farm management, and agricultural land was often left barren (Bastola et al. 2015). In the case of the population which has stayed behind, we see more severe effects on women, as they suffer more often from psychological impacts while adapting to climate change. Since the publication of Census 2011, it is estimated about $8 \%$ of the total population have migrated for employment to foreign countries. The total remittances contribute about $29.1 \%$ of the national economy (in 2013/2014) (GoN 2014). To build local resilience through income diversification, the Government of Nepal under the Foreign Employment Policy 2012 directs establishment of labour banks. These institutions are yet to be implemented on the ground. Unless policy frameworks with institutional arrangements are in place, outmigration will cause those staying behind, particularly women, children, the elderly, and the physically disabled, to remain vulnerable to climate variability (Bettini and Gioli 2015).

In the male outmigration situation, some women have begun to strengthen their access and control over the economic gains from agriculture (across all central regions as shown in Fig. 14.2), and the driver may not necessarily be a consequence of male outmigration. There are several other factors that are important determinants of gendered vulnerability to climate variability, including geography, religion, class, and ethnic divisions (Bastola et al. 2015; Maraseni 2012). Until now there has been little focus on women's capacity, their critical role in managing production in the absence of the male population (Skinner 2011). Therefore, experiences of climate variability are not always disproportionately negative or only negative for women, but in most situations women are likely to experience disproportionately the negative impacts due to the existing social gender structures that favour men (Bhattarai et al. 2015, p. 122).

\subsubsection{Pakistan-Disaster Response Policies Versus Practice}

Case studies from Pakistan reflect the lack of focus on gender dimensions during disaster response implementation despite gender sensitive policies and guidelines. The disaster management authorities have taken useful steps for making 
Fig. 14.2 Number of women and men engaged in various agricultural activities by region et al. 2015). Notes The number denotes total number of respondents for a given activity (Primary data source Bastola

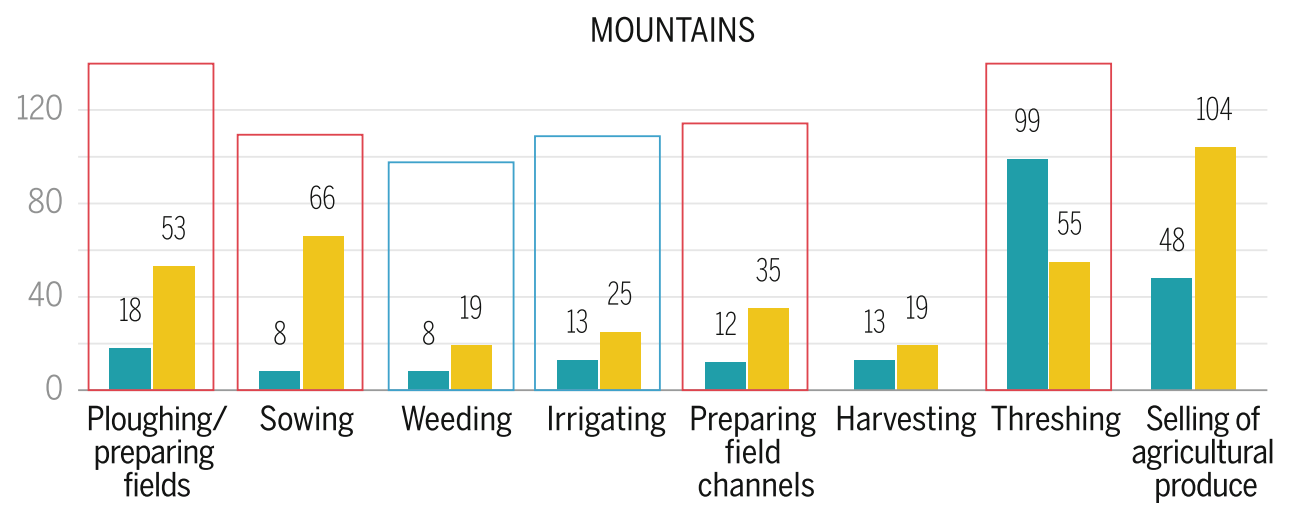

HILLS

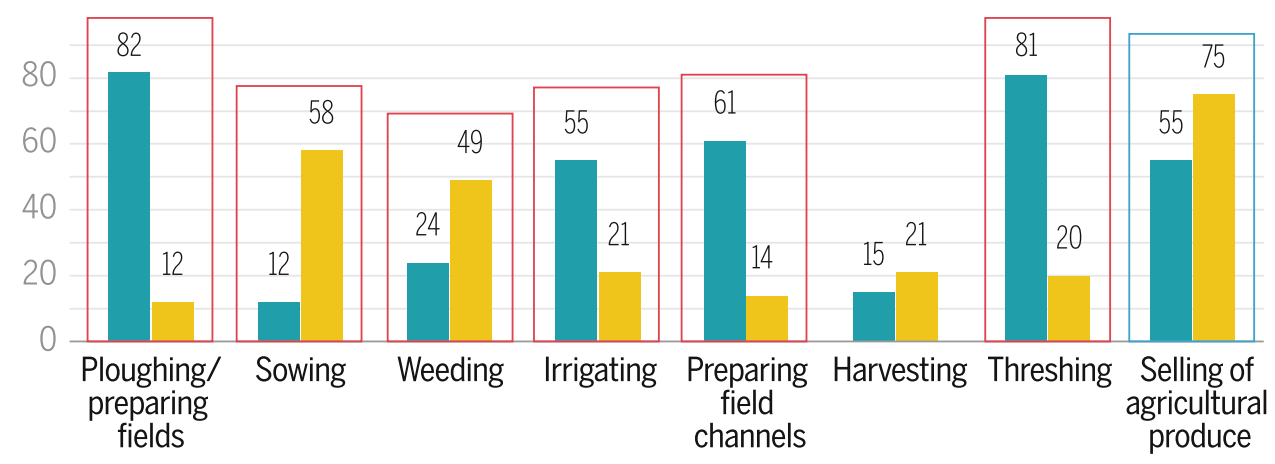

TERAI

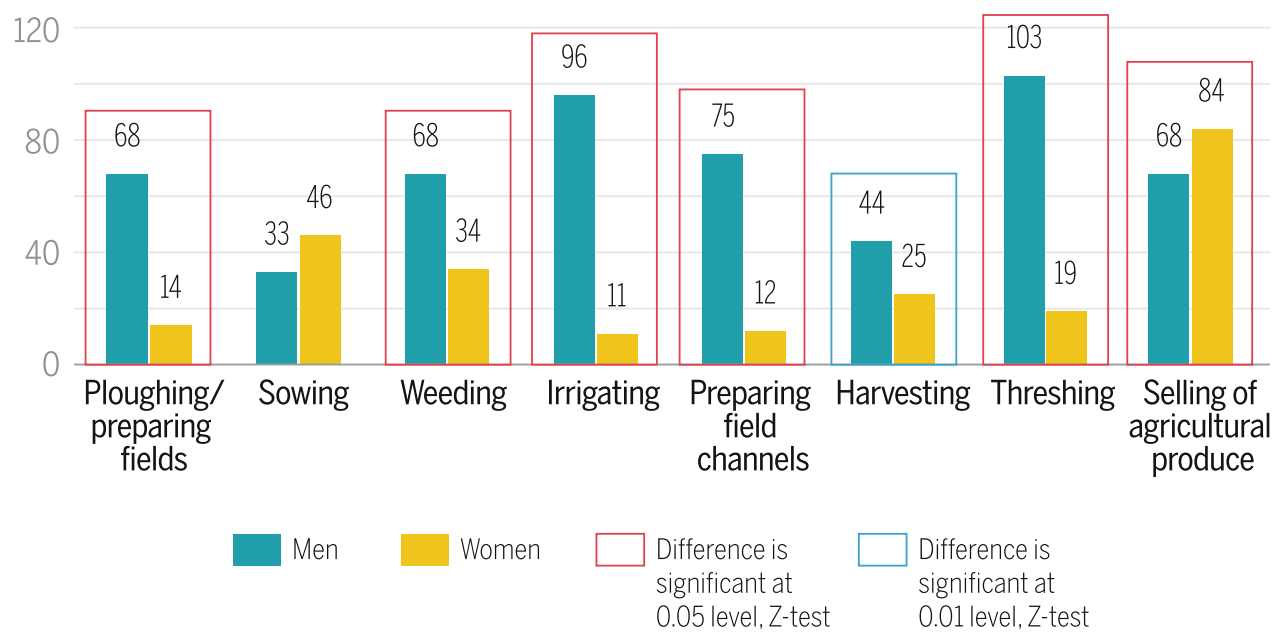

disaster response and recovery gender sensitive. For instance, the National Disaster Management Authority (NDMA) has developed guidelines, 'Disaster Risk Reduction (DRR), Gender and Environment', with an objective to provide disaster managers with the initial tools for taking care of the infrastructure and social vulnerability during the disaster. At the provincial level, the Provincial Disaster Management Authority (PDMA) have established 'Gender and Child Cells' and developed various codes of conduct to support gender integration during a humanitarian response.
However, despite this progress, humanitarian response implementation to date has not sufficiently focused on significant gender dimensions (Hamid and Afzal 2013). Gilgit-Baltistan's Contingency Plan for Floods reveals that vulnerable groups (women, children, elderly, and disabled persons) are neglected in the planning and conduct of relief operations (GDMA 2015, p. 7).

A survey of the literature in Pakistan on this topic stresses the need for gender disaggregated data. Though effective adaptation strategies need to address fundamental gender 
disparities in the disaster relief process, in the absence of robust data, gender analyses will remain inadequate and establishing gender-sensitive needs, response, recovery, and rehabilitation almost impossible (IFRC 2007). At present, only Khyber Pakhtunkhwa PDMA has begun to collect gender disaggregated data. Among their early findings, they state that more women than men died in the rains and cyclone of 2015 (PDMA/KP 2015).

Studies also show that post-disaster processes of consultation were also poor in terms of collecting gender disaggregated data. Only men were solicited for information. Consultations with children, pregnant women, the disabled, and other vulnerable groups were insignificant. Most explanations for this oversight highlighted by various studies included masculine culture and male domination in most formal government institutions (including N/PMDAs, irrigation, WAPDA, and disaster-related district administrations), lack of capacity in terms of integrating gender, and sociocultural barriers that restrict men's access to vulnerable groups particularly women (Shah 2012; Hamid and Afzal 2013; Shah and Memon 2012).

Responses from the field, especially poor communities affected by floods, also reveal that gender is a largely neglected aspect of community infrastructure planning and provision (Shah 2012). However, women, children, the elderly, and the disabled pay a particularly high price for this lack of sensitive infrastructure development. After the floods of 2010, it was observed that floods came suddenly, and without an early warning system there was hardly any time for communities to make a timely and planned evacuation (UNIFEM 2010). An analysis of early warning systems conducted by LEAD Pakistan (2015) found that 88 out of the 145 districts of Pakistan were at risk for flood, but only 39 districts were covered by early warning systems. It is noteworthy that the majority of women and girls had no independent access to the tools used for communicating flood warnings, such as loudspeakers in mosques, mobile phones, and FM radio. Therefore, merely providing early flood warnings through various media sources may not necessarily ensure that women and other vulnerable groups have information on which to take action (Mustafa et al. 2015).

\subsubsection{Social Structure, Gender, and Climate Change: Differential Vulnerabilities}

Climate change conditions have also intensified competition over water and agricultural resources. Tetlay and Raza (1998) examined growing outmigration for employment with households increasingly becoming "female managed", especially in the HKH. The livelihoods of the people in the region are based on agriculture, livestock raising, management of natural resources, migration, labour-intensive household management, and income generation through small-scale trade and wage and casual labour (Leduc and Shrestha 2008). The diminishing subsistence prospects and underemployment in rural areas have pushed (mainly) men into seeking alternative livelihoods in off-farm domains resulting in an increase in, and intensification of, women's work and role as primary supporters of homesteads and family farms (Bose 2000; Gurung 1999; Leduc 2009; Mehta 1996; Sidh and Basu 2011). Thus, over the course of the past decades, male outmigration in mountain agriculture has emerged as one of the most pressing issues facing productivity and food security. But the ownership of natural resources like land and forest is confined to more powerful segments of society, primarily men. The agricultural, technical, and institutional support such as extension, credit, and subsidies are offered mainly to men, who are household heads in most cases.

Women and minority groups across the $\mathrm{HKH}$ are the most affected by the impacts of climate change. In China, the "one household, two sector" phenomenon is often seen as an outcome of globalisation and a changing environment. Women who stay behind take on the agricultural work in addition to other domestic responsibilities to secure the food basket. Case studies from the HKH clearly indicate there is an increasing proportion of 'feminisation' of labour as men out-migrate in search of work in response to climate variability as well as other socioeconomic factors, which makes agriculture less predictable and reliable. Therefore, cases from China show that women are starting to play key roles in managing natural resources for food security, climate change adaptation, and transition to a green economy.

Because the $\mathrm{HKH}$ stands at a heightened risk for natural disasters due to climate change impacts, it has once again raised serious concerns on gender narratives. The question is how such factors intersect with differential vulnerabilities in the event of floods, cyclones, landslides, earthquakes, and other disasters. Drawing on experiences from the cases of Myanmar and Pakistan, the impacts of disasters have a detrimental effect on different groups of women and marginalised groups which adds to an already formidable burden to provide food, water, and health care. Also, these events expose vulnerable groups to a high risk of violence and bring added livelihood insecurity (Brody et al. 2008; IFRC 2007; Neumayer and Plümper 2007; Parikh 2007; Vincent et al. 2010).

The differential impact of climate on gender is apparent in the HKH. For example, a first form of 'gendered' vulnerability to climate change relates to labour (Sugden et al. 2014, p. vii)—women's workload increases as distances travelled by women increase to access natural resources (such as water, fuelwood, fodder, food, pastures, medicinal plants, fuel, and crops) and as production schedules are affected due to changing environments and climate conditions (Bhattarai et al. 2015; Sugden et al. 2014). Thus it is important to mainstream gender-sensitive approaches when addressing 
environmental issues in the HKH. Several crucial points need to be addressed. First, there is a need to identify vulnerable groups in terms of age, disabilities, and social and religious groups and cater to their needs in disaster response to avoid further marginalisation in the process. Second, strengthening of the collaboration between government authorities and humanitarian organizations is required for the gender responsiveness of the relief programs. I/NGOs can play a role to build the capacity of government, as well as communities, especially in gender-inclusive development.

In spite of these recognised needs, gender-inclusive planning and implementation are not integral to development processes in the developing world (Moser 2012). The HKH is not devoid of this phenomenon. It is also important to recognise the traditional cultures that are women centric and female managed, and if we are to properly address the challenges to mountain communities, this means robust data will be required to confront fundamental gender disparities (Gurung 1998; Tulachan 2001).

What is most critical to consider is context - the context in which the changes are taking place and that is resulting in diverse vulnerabilities and impacts. This means there is a need to think more critically and creatively about the broader implications of different vulnerabilities and impacts and ways to address them.

\subsection{Environmental Governance and Gender in the HKH: A Cautious View on Green Growth Visions}

Environmental governance in the HKH is increasingly tailored towards an outlook of green economic growth. The impetus towards green economic growth has been accelerated as a mitigating response to climate change. This poses old and new questions regarding the shaky connections between social wellbeing, equity, and efforts to 'green' economies and sustainable development as a whole. Policies and programs have long focused on the technical aspects of climate change, privileging, for instance, an efficient use of natural resources over social aspects, such as issues of equality, discrimination, and empowerment. They have given importance to engaging women to make development work efficient rather than to bring about change in unequal power and gender relations by addressing the power relations between men and women. Therefore, it is important that the nature of interventions shift from "technocratic quick-fix[es] to gender inequalities [-] interventions that make unrealistic expectations on women [already] in poverty - to interventions that understand history and context better, ... [and] recognise not only women and their vulnerabilities, but equally men and their masculinities. ... [T]his calls for a "long-haul, deeply political challenge”' (ODI 2007).
From a gender perspective, the two-way relationship between gender relations and environmental change needs to be understood in the context of the green economy. Gender relations have a powerful influence on how environments are used and managed, and hence on patterns of ecological change over time (Leach et al. 1995), and similarly environmental trends and shocks also have an impact on gender relations. Most of the time, there are direct implications such as forest or water degradation and depletion that alter the gendered distribution of resources or encourage gender-based coping strategies.

The term 'green economy' is defined as an economy that results in improved human wellbeing and social equity, while significantly reducing environmental risks and ecological scarcities. It is low carbon, resource efficient, and socially inclusive (Stone 2011, p. 1-2). Advocates state that a move towards a green economy can be profitable where economic growth will be healthier, stronger, and more vigorous with this transformation rather than without it (Brockington 2012). However, critiques of the green economy (Bullard and Müller 2012; Gupta and Agarwal 2013; Kosoy et al. 2012) argue that politico-economic and cultural constraints need to be considered to create strategies that are successful in achieving the goal of ending environmental degradation and reducing poverty.

'Green growth' has evolved into a number of contemporary forms in the region, such as heightened forest conservation efforts to spur carbon trading, bio-energy development, natural park enclosures, increased water regulation to ensure efficient uses largely for productive ends, and payments for ecosystem services. Research increasingly shows there may be difficult trade-offs between green growth, environmental sustainability, and social wellbeing (Fairhead et al. 2012; Harcourt and Nelson 2015). As a result, there is growing ambivalence around some so-called green projects. For instance, hydropower development is being promoted as a source of clean energy, but research has demonstrated it may in fact sidestep the wellbeing needs of dislocated communities. Forestry options such as payment-for-ecosystem services and REDD+, as well as standards and certifications applied to the carbon trade and offset projects are envisaged to ensure fair practices, but may implicitly tap women as a reserve, but cheap, army of labour with benefits that remain unclear to them.

What seems to be emerging is a new regime of appropriating and managing both nature and society for so-called 'green' ends. This new green regime builds on earlier weaknesses of community-based natural resource management. It fails to correct social/gender exclusionary practices and continues to appropriate women's undervalued labour for green projects. This regime also builds on earlier tokenistic practices to involve women as a social group, often resorting to 'ticking the box' exercises to legitimize 
them as an accounted-for constituency. Despite earlier intentions to apply bottom-up approaches, the state continues to employ community-based natural resource management as an instrument of control of both nature and society, an effort that was once touted as "bureaucratizing communities" (Gauld 2000), increasingly turning these communities into corporate appendages of the state. In today's natural resource management regimes, more emphasis is also turning towards employing techno-scientific approaches in mitigating climate change and addressing green growth goals (MacGregor 2010).

Current efforts to mitigate climate change and spur green growth emphasize efficient management based on scientific, financial, and market-based goals and principles to drive natural resource management (Paudel and Paudel 2013). Green growth projects and natural resource management today attempt to mitigate and adapt to climate change in ways that are de-politicized, 'masculinized', and male dominated, in an effort to appropriate and 'tame unruly nature' (MacGregor 2010; Taylor 2014; Tschakert 2012). This approach in many ways creates persistent silences around the political economic drivers of climate change, focusing almost entirely on its technical aspects and solutions.

Therefore, the 'eagle-eye' science of popular climate knowledge, science, and environmental governance interventions needs to be complemented by locally contextual 'toad-eye' science and interventions (Gyawali and Thompson 2016). Sustainable development in the HKH demands socially and gender-inclusive climate science and environmental governance policies and strategies.

To assess the status of governance of the environment and green economic growth from a gender and social inclusion perspective, this section highlights first the status of gender mainstreaming at the policy and institutional levels and second how these policies tend to unfold on the ground. Then, the current promotion of hydropower development in the $\mathrm{HKH}$ as green development is critically assessed, and a plea is made for a more conscious reflection on the performance of professionals and the linkages between men, 'masculinity', and power in knowledge production in environmental governance itself.

\subsubsection{Gender Mainstreaming Policies and Institutions}

Most countries in the HKH have called for or claimed to have mainstreamed gender in the various sectors within the domain of environmental governance. Even in sectors in which inequities and social exclusion have long been rendered invisible - such as irrigation and water resources planning - gender and women have now earned a legitimate place in research and policy agendas (Zwarteveen 2006). However, there is little to celebrate when we consider the manner in which gender is interpreted and integrated in climate interventions and policies. The attempts to 'gender mainstream' in climate policies, strategies, and interventions remain plagued by simplistic, apolitical interpretations of gender: 'gender as women', the paradoxical positioning of homogenous categories of 'mountain women' as being both 'vulnerable victims' of climate change as well as 'formidable champions' of climate adaptation, and the idea that engaging women on projects is taking care of women's needs and empowering women.

Thus, the current status of gender mainstreaming in environmental governance is not only a clear measure of the progress that has been made, but also a reason for deep concern. Two cases - one from Pakistan and one from China - show the largest reason for concern is that gender mainstreaming appears to have been achieved in environmental governance by adopting a very narrow and simplified concept of 'gender'. The term is essentially used as a synonym for 'poor rural women'. The habit of equating gender issues with grassroots women's issues in development and the modernist idea that women's empowerment can be implemented top down, seems to do more harm than good (Liebrand 2014). Overall, the trend is that women are treated as victims - not as agents.

The case of Pakistan highlights especially that most progressive gender policies in environmental governance in the $\mathrm{HKH}$ are accompanied by a structural lack of financial resources or (human) skills and capacities In other words, gender is often not considered a priority in environmental management and climate change policies. Generally, it can be observed that state agencies in various HKH countries have committed themselves to the promotion of gender equality, and they make a proclaimed effort to make it happen, but simultaneously, there is a persistent impression that gender mainstreaming is (also) promoted as a form of window dressing.

\subsubsection{Pakistan}

Pakistan launched its Climate Change Policy in 2012, with an aim to ensure that climate change is mainstreamed in the economically and socially vulnerable sectors of the economy and to steer Pakistan towards climate resilient development. In spite of numerous challenges, Pakistan has initiated many other policies to address climate change and natural resources management, such as the National Water Policy, National Drinking Water Policy, National Climate Change Policy, the National Sanitation Policy, and others. All these policies present frameworks to address the key challenges of climate change and natural resource management at a national level and serve as guiding principles to the 
provinces to initiate their own policies to protect natural and environmental resources. ${ }^{2}$ A similar trend is visible in other HKH countries.

Recognising women and other vulnerable groups as powerful agents of change, and the differential impact of climate change on gender, most of the aforementioned policies do suggest various measures for gender mainstreaming (Hamid and Afzal 2013; SPDC 2015). For instance, the third objective of the climate change policy focuses on pro-poor gender-sensitive adaptation while also promoting mitigation to the extent possible. The National Drinking Water Policy, the National Sanitation Policy, and others acknowledge, in particular, women's active role in water management. Furthermore, Pakistan is also a signatory to several international norms and standards that lay the foundation for gender equality. The Government of Pakistan has also allocated employment quotas for women in provincial and federal institutions (Rai et al. 2007).

But Pakistan ranks as the world's second-lowest country - 144 out of 145 countries, according to the 2015 Global Gender Gap report - in terms of gender equality and the equitable division of resources and opportunities among men and women. Major fields like climate change, disaster, water, irrigation, mitigation, and the environment in Pakistan are still considered a male domain, outside the purview of women (Shah and Memon 2012). The fact is, the majority of formal government institutions and structures dealing in climate change and natural resource management are highly male dominated. The marginalisation of women was evident in the staffing patterns of these organizations (Shah 2012; Hamid and Afzal 2013). There are no formal mechanisms to ensure a gender balance in higher level positions in climate change, water, and irrigation bureaucracies. Therefore, in the absence of strong implementation, gender mainstreaming of governance structures does not, for the most part, translate into practice.

It is also important to understand that most government institutions have limited financial and technical resources/capacity available especially in terms of integrating gender into climate change planning (SPDC 2015). This omission can further result in poor response in terms of meeting the needs of marginalised groups. The literature on gender, climate change, and disaster in Pakistan includes various well-documented experiences that highlight the victimisation of women and other vulnerable groups during emergencies, as well as the undermining of their productive role in community building after disasters (Akçar 2001; Bari

\footnotetext{
${ }^{2}$ After the 18 th constitutional amendment, provinces in Pakistan are now empowered to initiate their own provincial policies and institutional arrangements.
}

1998; Enarson 1999; Morrow and Phillips 1999; Shah 2012).

\subsubsection{China}

The Chinese government has increasingly acknowledged how poverty intertwines with biological and cultural diversity through the government's ecological civilization strategy and green social transition. Although China has achieved significant poverty reduction in the last decade, poverty levels remain high, at roughly 200 million people, according to international poverty standards. There are 14 state-identified poverty areas, mostly in remote mountain areas, which are at the same time well-known for their rich biological and ethnic diversity, diversified landscapes, and valuable bio-cultural heritage. China is active in climate change adaptation as well and launched the South-South Programme during COP 21 in Paris in 2015 to support other developing countries through the South-South Collaborative Fund for Climate Change Adaptation. China has a large national Climate Change Adaptation Plan using ecosystem-based adaptation as a major methodology and scientific technologies as key tools. Yet, consideration and integration of gender analysis for inclusion in community-based adaptation and women's roles in adaptation is limited. Further study on the links between and integration of ecosystem-based adaptation and community-based adaptation is urgently needed. The previously described case studies and the examples from Guangxi and Yunnan (Sect. 2.1) provide both strong examples for implementing community-based gender-sensitive biodiversity management and important survey data at the policy and action levels.

\subsubsection{How Policies for Gender Mainstreaming and Social Inclusion Unfold on the Ground}

Policies for gender mainstreaming and social inclusion in environmental governance on the ground are complex and diverse. As illustrated by cases from China (community-based biodiversity management) and Nepal (community forestry), current policies for user participation and community-based management inadequately address gender concerns, although these policies often explicitly seek to address them. The inclusion of some women as representatives of user committees has, by and large, not altered the marginalisation and social exclusion of women from these groups. One reason is that government agencies use policies of decentralization, user participation, and community-based management as a means to exercise control, regulation, and state power. 


\subsubsection{Women's Role in Seed and Food Security in China's Mountains}

Farming women play crucial custodial roles in seed and food diversity all over the world. Women's reproductive roles as mothers and family keepers build their interest, expertise, and knowledge in seeds and food biodiversity issues. They are making an essential contribution to the resilience and continuity of the world's ecologic and food systems. Survey data in southwest China confirms this: Amongst small holding farmers, $62 \%$ of women play a role in seed selection and storage (Song and Zhang 2015).

In order to help farmers in remote villages conserve seeds and improve their preferred landraces and participatory plant breeding (PPB) varieties, both to save seed cost and to create incentive and redirect benefits to PPB farmers, a team initiated community-based conservation and a participatory variety selection trial and seed production of a PPB variety, Guinuo 2006, in a number of trial villages in Guangxi. This PPB hybrid seed production has been carried out by women farmers' groups in this area since 2005 and has expanded to women's groups in Stone Village in Yunnan through farmer-to-farmer exchanges facilitated by the project team.

The PPB activities in Stone Village have conserved more than 50 food crop varieties and improved 10 drought-resistant or quality landraces, and the women's groups have generated a significant amount of money from seed production. The groups have also started learning ecological and organic farming practices from Guzhai village and plan to register a women's farmer cooperatives next year.

Both village case studies illustrate an important rural development pathways in mountainous areas of China: community-based and women-led cooperative, diversified agriculture combined with strong horizontal integration (Song et al. 2014). Together, these ideas represent "a locally-driven empowerment process in which farmers, led by women, have improved their capacity to deliberate about choices of action, experiment with options, create new practices, and enlarge the network of horizontal relationships, and thus obtain more autonomy in realizing their aspirations according to their own agendas" (Song and Vernooy 2010).

Both cases benefit from strong technical support and capacity building, accompanied by targeted research. The project support for both the community cases in Guangxi and Yunnan is more focused on broad rural development than on commercial motives. The work also benefits from interactions and collaborations with other cooperatives, restaurants, NGOs, research centres and universities, and the government's agricultural extension service. The process of expansion is a capacity-building and empowering process for these women-led cooperatives and self-directed communities.

\subsubsection{Community Forestry and Hydropower in Nepal}

\section{(a) Community Forestry Programme}

Nepal's Community Forestry Programme (CFP) has been hailed as an environmentally and socially transformative initiative, but in fact, has in many ways not benefited the poor. Some scholars allege that community forest user groups (CFUGs) have actually resulted in "restricting access to resources by the poor" (Gupta et al. 2011) and as such, CFP has not really ensured equity, inclusion, or gender sensitivity (Neupane 2003; Paudel 2012).

Following the conception of the community participatory approach, the early 1990s saw a wave of popularity in decentralized formal arrangements for forest governance as governments realized the need to transfer responsibilities to local institutions and bestow decision-making powers on communities for better resource management outcomes. Hence, over the past few decades, there have been many devolutionary initiatives in a number of the HKH countries to bring about gender and social inclusion. However, in tracing the trajectory of these initiatives, we find that policies and programmes establishing local forest governance institutions were gender blind and communities were treated as an ungendered entity (Agarwal 2000; Das 2011; Arora-Jonsson 2014). Only in later years, with changes in approaches to decentralized governance and feminist criticism of such policies, were steps taken by the government to integrate gender equality concerns in programmes and schemes at different levels (Tyagi and Das 2017, p. 239).

From amongst such initiatives, Nepal's model of community forestry as a green governance initiative has been hailed as the most successful, transformative, and people-oriented model of local-level forest governance for its social as well as environmental objectives. CFP in Nepal started in the 1970s and strengthened through later policy and legal instruments such as the Master Plan for the Forestry Sector 1988, the Forest Act 1993, and the Forest Regulation of 1995. This legislation provided favourable conditions for the successful handover of national forests to local communities. As such, the CFP has been the largest and longest participatory green initiative, with $40 \%$ of Nepal's population belonging to more than 15,000 CFUGs which are involved in managing 25\% of the country's forest area (Gupta et al. 2011; Karki et al. 2011). With the shift in property rights from the state to communities, CFUGs have been able to exercise a bundle of property rights regarding access, use, and management of national forests. The CFP goes beyond managing forests for environmental and economic benefits; it has become an important instrument and process for social change-empowering the marginalised (Gupta et al. 2011). 
In Nepal, the Poverty Reduction Strategy Paper of 2002 and the Millennium Development Goals regard the CFP as a suitable instrument for achieving the country's poverty reduction goal (Kanel 2007), while international development agencies and governments view it as a tool for poverty reduction and sustainable natural resource management (Gupta et al. 2011). The programme has been hailed as "inclusive and equitable" as well as "able to address socio-political and environmental concerns at the national and regional levels" (Karki et al. 2011, p. 22). CFUGs were first set up as projects but are now recognized as institutions. A number of cases have been celebrated for successfully arresting deforestation, helping to improve forest cover, and fomenting "genuine local participation and support" (Ibid, p. 23). Where there has been a greater presence of women in community forestry institutions, many statistically demonstrable benefits, such as enhancement of women's effective participation in decision making, women's stronger influence in the nature of decisions made, and women's roles in improving forest conservation outcomes, have been noted (Agarwal 2010).

However, the CFP has been critiqued at two levels: its process and its inclusion and participation. Agrawal et al. (1999, p. 2) describe the CFP as a "highly political process since it seeks to redistribute power and resources within the territorial confines of a given nation-state". Although the CFP seems progressive in nature the government still holds the power. Sections 67 and 68 of the Forest Act state that the government has the ownership of all types of community-managed forests and has discretionary power to alter the use of forestland and to withdraw the community forest on certain conditions (HMGN 1993). The management plan of CFUGs is a contractual document giving tenure rights over forest resources, and violation of any provision of the management plan by any member of the CFUG can affect the tenure rights of all members of the group. These administrative powers are held by the District Forest Officer (Gupta et al. 2011). Ultimately, this means that communities have only usufruct rights over the forests they nurture and guard; the government has agreed only to hand over the degraded hill forests for restoration and conservation, while it maintains control over the richer forests of the terai. The Federation of Community Forest Users-Nepal (FECOFUN), a network of CFUGs and forestry-related NGOs, has criticized the government on this point. These conditions have made CFUGs insecure about their tenure in community forestry and many communities have lost interest in participating.

On the inclusion front, numerous studies indicate that the extent of change is actually limited within large numbers of women, the poor, and excluded caste and ethnic groups who participated in community forestry processes and institutions (Agarwal 2009; Bushley 2002; Chhetri 2001; Lama and Buchy 2002; Nightingale 2002; Parajuli et al. 2010; Paudyal
2008; Uprety et al. 2012; Winrock 2002; Yadav et al. 2008). These groups benefited less from community forestry than wealthier and influential households: They could obtain free fuelwood and other non-timber forest products from the same forests before the introduction of the CFP; once the CFP declared these forests as community forests their access was limited and, therefore, many communities and groups were not interested in participating (Maharjan 1998; Malla et al. 2003). Similarly, procedures for electing the committee and decision makers through consensus and voting also resulted in well-off male and upper caste people dominating the CFUGs, which meant that powerful elites of the community shaped the rules of access to forest resources due to the prevailing sociocultural norms and barriers that influence participation in these institutions along social axes of differentiation such as class, caste, ethnicity and age (Agarwal 1997; Nightingale 2002). The Ministry of Forests and Soil Conservation in its 2013 review report cites prevailing cultural norms as the reason women's access to and influence of decision-making processes is muted, despite CFP's efforts to ensure representation of women in key decision-making positions. Furthermore, time constraints on women for domestic work limit their participation (Agarwal 2010). Staddon et al. (2015, p. 268) document a participatory community forestry project in the middle hills of eastern Nepal as a case of a well-intentioned development gone wrong. Although the aim was to invite local communities to participate, what unfolded were "multiple tyrannies" (Ibid, p. 274, 276). They found "uneven participation that provided minimal benefits to the most marginalized (women and those who are illiterate)" and that while many did "participate" as per the terms of engagement defined in a rather top-down fashion, there was - as in many other projects - an "inadvertent reinforc[ing of] existing power relations, diverting control away from communities and towards forestry authorities" (Ibid.).

We can also see that the experiences of 'women's only' CFUGs are not altogether positive. Studies have shown there is often increased marginalisation of these organizations and little to no increase in the empowerment of women (Buchy and Rai 2008; Rai and Buchy 2004; Seeley 1996). Agarwal (2010) found that 'women's only' CFUGs were allocated poorer forests compared to mixed-sex groups.

When analysed from a gender lens, institutions that seem be equitable, efficient and sustainable are not really so (Agarwal 2000) and that efforts towards gender mainstreaming in forest governance and policy have been far from desirable (Tyagi and Das 2017, p. 235). Meanwhile, current policy thrusts on gender mainstreaming in natural resource governance have considered gender as synonymous to women (Arora-Jonsson 2014). This understanding is problematic in that it implies gender as an issue for women only. Finally, gender mainstreaming as applied mostly results in 
adding more female members to local governance systems (Mukhopadhyay 2004). In this way, gender mainstreaming has been limited by its efficiency and functional approach rather than a structural approach towards empowerment. The entire structural and power relationship between genders remains almost untouched in policy and practice.

Gupta et al. (2011) argue that the since 2001, when discourse on environmentalism became a global issue, the involvement of non-state actors, such as donors and NGOs, increased and that these actors changed their operational strategy during Nepal's decade-long political insurgency. Although these influential non-state actors were aware of power relationships, they did not challenge them but rather used them for two purposes: to establish and advance their organization, and to establish their role as service providers to the forest sector and donors. On the other hand, non-state actors such as Federation of community Forestry Users Nepal (FECOFUN), who have been supported by donors for policy activities, had little ability to raise the agenda of challenging power issues within forestry governance because they depended on donors for financial and intellectual support. In this way, the "dynamics and complexity of actors' interactions, perceptions and power/knowledge in participatory forestry play a role in the exclusion of the poor, dalits, ${ }^{3}$ and other disadvantaged social groups" (Gupta et al. 2011).

\section{(b) Hydropower}

The recent surge in hydropower development as a climate-mitigating strategy makes for an interesting case to analyse the 'depoliticised' framing and positioning of gender in two processes currently emblematic for the HKH. Hydropower development is articulately positioned and presented as being climate mitigating and, as such, hydropower projects [producing renewable and clean energy] qualify for top-up funding through the Clean Development Mechanism. Hydropower has emerged in the region as an economically viable and sustainable energy option and country governments and donor agencies are increasingly in support of hydropower, citing other numerous benefits, apart from energy generation, provided by hydropower dams such as flood control and irrigation, which would also contribute to poverty alleviation and sustainable development (Shrestha et al. 2016).

However, hydropower development in the region has also led to "adverse socio-environmental impacts. ... particularly common at the local level", primarily because hydropower projects are more concerned with "national and regional

\footnotetext{
${ }^{3}$ Dalit is the name given to the lowest class of people in traditional Indian society, who were formally referred to as "the untouchables", falling altogether outside the Hindu caste categories and subject to extensive social restrictions.
}

economic priorities" and pay "little attention to the adverse impacts on affected local populations (mostly mountain communities)" (Shrestha et al. 2016, p. 1). Furthermore, hydropower development policies and strategies in the region pay little attention to gender, regardless of the climate merits assigned to clean energy development. While there is significant attention to the risks of hydropower development in these regions for local communities, the analytical scale of the 'local' remains essentially unpacked. While hydropower is indeed renewable, the waterscape is often irreversibly changed by the processes of generating hydropower. What might be the social, economic, and environmental costs of large dam development in a region that is said to be not only geologically and ecologically unique but also politically fragile, with ethnic and cultural tensions and political faults corresponding to international and national boundaries?

The Shrestha et al. (2016) report on the benefit sharing mechanisms ${ }^{4}$ in Nepal's hydropower sector show that "while benefit-sharing programmes generally seek to share benefits equally across project-affected populations. ... certain kinds of people have less access to the benefits of hydropower development than others" (p. 41). Women are among these groups who are under-represented in the process of hydropower development in terms of stakeholder consultation, local hiring and employment, establishing local development priorities, and local governance. Women from marginalised groups (Janajati, ${ }^{5}$ dalit, ultra-poor, and disabled women) experience further disadvantage due to social power hierarchies.

The Shrestha report examines the benefit sharing mechanisms of hydropower development and concludes that

\footnotetext{
${ }^{4}$ In the hydropower sector, benefit sharing mechanism would mean ways and methods to share the profits, but more important, the advantages derived from the hydropower development by the companies. The early practice of benefit sharing was 'trickle down' to local communities, whereby broader national and regional economic development was expected to bring the dividends of development to local citizens. Later, the practice moved on to compensation and mitigation for minimizing the negative impacts of projects, and mechanisms were designed to ensure that individuals and communities adversely impacted by hydropower development were compensated for any losses sustained. More recently, the emphasis is on sustainable development, therefore, benefit sharing mechanisms now go beyond mitigation and compensation "to maximize development benefits and more equitable outcomes, and working directly with local communities to increase investment effectiveness" (Shrestha et al. 2016:7).

${ }^{5}$ Adivasi/Janajatis: People or communities having their own mother tongue and traditional customs, distinct cultural identity, social structure, and written or oral history. They are interchangeably referred to as "Janajatis," "ethnic groups," and "indigenous nationalities." The government identified 59 groups as indigenous nationalities and these are categorized into five groups based on their economic and sociocultural status. These include "endangered," "highly marginalized," "marginalized," "disadvantaged," and "advanced" groups. Newars and Thakalis are the only two groups classified as "advanced" groups (ADB 2010).
} 
"patterns of social exclusion based on gender, caste, ethnicity, and class were apparent" (41). The authors note that women receive considerably fewer direct benefits in both employment and training. Furthermore, women are provided training in gender-stereotypical skills such as knitting, cooking, and weaving. The report states that "these issues reflect a larger problem with gender inequity: The collective voice of women is routinely subjugated in local processes of decision-making about hydropower projects" (25).

The report (40) outlines the following gender and social inequities that are evident during the process of hydropower development:

- Uneven patterns of awareness and information about stakeholder rights

- Unequal participation in community consultations and decision making about hydropower development, leading to the prioritization of some agenda and the subjugation of others

- Uneven distribution of impacts related to hydropower development, as certain subpopulations and social groups are disproportionately affected or economically dislocated

- Unequal ability to mobilize for individual benefits (i.e., seeking employment, participating in training programmes, or purchasing project shares)

- Informal inequalities in the distribution of benefits notionally shared by communities (e.g., community development programmes, royalties) due to unequal access to public facilities and patterns of social hierarchy.

\subsubsection{Professionals, Knowledge, and Masculinities: A Scale Challenge in NRM Governance}

In environmental governance, many knowledge and policy domains are treated as fields of engineering and technology, especially in the field of natural resource management (Adhikary 1995). The domain of irrigation and water governance is one example (Liebrand 2014; Zwarteveen 2006). It is an area of expertise that historically is managed as a field of irrigation engineering, particularly in Asia (Ongsakul et al. 2012). In this context, several fields in environmental governance have been qualified by feminist scholars as 'masculine'. For clarification, masculinity is not just about 'men'; it is also about ideas of supremacy and modernist convictions in engineering to which notions of power are attached. It is true that male professionals have traditionally dominated the field of engineering and technology - their presence in the profession is considered 'normal' (Gupta 2007; Kulkarni et al. 2009; Nair 2012; Parikh and Sukhatme 2004). But there also exists a strong epistemic tradition in environmental governance, in fields such as irrigation and water expert thinking, that sees the world as uniform, makeable, and manageable (Zwarteveen 2011). Consequently, it has long rendered thinking and speaking about women (and men) irrelevant. It is also in this 'masculine' professional culture that policies such as Integrated Water Resources Management (IWRM) gain meaning and that knowledge on climate change adaptation acquires legitimacy.

The domination of engineering knowledge and the 'masculinity' of professional cultures in natural resources management (NRM) can be considered a scale challenge ${ }^{6}$ in environmental governance (Liebrand 2010). For the HKH, this is reason for great concern. It means that there is a structural mismatch between actual realities in the field and expectations and administrative realities at the policy level. For instance, the policy objective in water governance to support livelihoods and create opportunities for all is undermined by a culture of 'masculinity' among water professionals. This means that complex 'problems' in the field, such as gender inequities in irrigation, are conceptualized as 'technical' or 'engineering' problems, based on ideals of the universal application of science and technology, and because 'hardware' solutions (e.g., canals, roads, pumps, and other infrastructure) are associated with 'real' development and with those professionals who hold this knowledge, i.e., mostly male engineers. The associations between men, 'masculinity', and power/knowledge in water governance partially explains why current measures to bridge the gap, between field and policy levels, continue to fall short of expectations.

In Nepal, for instance, the Department of Irrigation has adopted policies and programmes in the past two decades to improve irrigation and water resource management. Recurring elements of these programmes include decentralization, user participation, women's inclusion and, more recently, public-private partnerships (Gautam 2006; Shukla and Sharma 1997; Singh et al. 2014). Yet Nepal's irrigation and water resources development sector continues to be characterized by infrastructure interventions that are typically proposed and executed by an elite class of male engineers; and because such interventions tend to be designed in such a way that they fit the existing national socioeconomic context (for instance, the construction of an irrigation system without implementing land reforms), persistent and historic injustices and social inequities along divisions of class, caste, and ethnicity and gender (DFID/WB 2006) are being reproduced through such hardware interventions.

More generally, more than three decades of mainstreaming gender in (water) development research and

\footnotetext{
${ }^{6} \mathrm{~A}$ scale challenge represents a situation in which the current combination of cross-scale and cross-level interactions threatens to undermine the resilience of a human-environment system (Cash et al. 2006).
} 
policy have failed to come to grips with 'masculinities' in the profession (Laurie 2005; Liebrand 2014). In spite of repeated calls by feminist researchers to address masculinities in NRM, engineers and experts in water planning still tend to be men and modernist convictions are rarely discussed and challenged in the promotion of science and technology (Zwarteveen 2008, 2011). Hence, in spite of critique, a question of 'what does it deliver', continues to guide most discussions on planned development-not if it delivers at all or what it means for different people and how it actually works in the field. A knowledge tradition that sees the world as uniform, makeable, and manageable remains the dominant model; and most development interpretations in research and policy, for instance, made by irrigation and water experts today continue to emphasise and attach greater value to knowledge and experiences that present the world as rational, universal, and genderless (Liebrand 2014).

As noted, 'masculinity' is not just about men. Women professionals in engineering can be gender-insensitive and male engineers can be gender champions. For example, some male engineers in the Department of Irrigation are found today who discuss gender issues professionally and rationally, working hard to meet social equity and gender goals in development (see Udas and Zwarteveen 2010). It also is visible that gender and women have earned a legitimate place in water research and irrigation policy agendas, but at the same time there is to date little reflection among professionals on development norms and 'masculinity' in environmental governance and how these influence, for instance, water expert thinking and the way experts see irrigation development and water resources management. To address this concern, a way forward is to increase a capacity in experts to reflect on their knowledge and professional practises; they need to internalize a conviction that knowledge and development is never neutral and value-free. One promising way to achieve this is to integrate social sciences knowledge more firmly in engineering and technical education, and to ensure a more diverse representation among professionals themselves, in terms of social background (e.g., more women professionals, more experts of marginalized classes, castes, and ethnicities) and disciplinary education (hiring more sociologists in engineering departments, for instance).

\subsection{Conclusion}

This chapter has shown that climate change and extreme weather have differential impacts on women and men in the HKH. The case studies confirm that women's experiences in the HKH are multiple, differentiated, and sometimes contradictory and, in some cases, effect new chains of vulnerability.

Women across different socioeconomic categories are disproportionately affected because of structural inequalities in the distribution of rights, assets, resources, and power based on repressive cultural rules and norms. As a result, women are often poorer and less educated than men and excluded from political and household decision-making processes at various scales that affect their lives. Today's technocratic programs include women in economic development; this inclusion is rationalized only by an appeal to economic gain. While the pursuit of economic efficiency can offer women economic opportunities, it does not fully address their unequal power relations with men, vis-à-vis equal wages for equal work, or the sharing of domestic work responsibilities. Accordingly, the focus needs to be more on context. This means not only recognition of women's vulnerabilities but also how gender roles and identities constructed for women as well as for men contribute to gender imbalances, inequalities, power, and privilege. Interventions must shift their attention to the structures that underlie gender inequality. This work calls for long-term political engagement.

A major problem is that empirical data on the impacts of climate change are often presented in aggregate terms, reflecting an unfounded assumption that climate change affects people uniformly. Policy makers need to acknowledge that experiences of climate change, and responses to climate change, are defined by intersecting factors of age, caste, class, gender, and ethnicity. Therefore, policy needs to support mechanisms for collection of disaggregated data. This will require the development of such mechanisms, which can be shared and communicated effectively.

At the same time it must be understood that gender disaggregated data have their uses and limits: They can indicate disparities and differences (uses), but there is a need to explore and understand the multi-scalar drivers of inequality. This requires highly textured studies - nested, multi-scalar, and historical - that ask compelling questions about power, identity, struggles, and exclusions using mixed quantitative and qualitative methods. Such studies are urgent if we want to address the gender gap and track progress according to the SDG targets.

Far too often, when programmes talk about addressing gender, they imply acting at the household or community levels by taking the poor women as 'volunteers'. They typically address women's practical gender needs, by associating women's needs and aspirations as small in size and subsistence-oriented, which, while an important entry point, often do not question the gender division of labour or access to resource rights and ownership. The consequence is that this creates an unsurpassable binary of scale between what happens in households and communities and the broader arena of strategic environmental decisions (Lahiri-Dutt 2014). Furthermore, such an approach ignores women's strategic needs that are critical to women's empowerment and ultimately to transformative change. Interventions must shift their attention to the structures that underlie gender inequality. 
While the creation of space for women to participate in natural resources management and governance is critical in terms of exercising voice and agency, policies must not further feminize responsibilities in ways that will add to, rather than reduce, environmental burdens for women. Women's engagement and participation in climate change policy making and on-the-ground interventions should follow a logic that is empowering and promotes women's rights - not one that is dictated solely by efficiency.

Making development and adaptation efforts more gender inclusive and socially inclusive will require addressing contextually determined relations of inequality at the household, community, and other institutional levels. Such efforts are more likely to lead to sustained, transformative outcomes when based on longitudinal studies that explore how climate change affects various groups of women and men, both separately and jointly. This work calls for long-term political engagement and will require consistent attention to addressing these complex relations of inequality to ensure and enable change. Unfortunately, there is no simple, easy way to reduce the complexities of gender inequality. Attention needs to be paid to such challenging dimensions of development practice if preparedness for climate and natural resource management is to address gendered divides and disparities. Without professional and critical self-reflection, we have little reason to assume that new policies will succeed any more than past efforts to increase gender equality, women's empowerment, social inclusion, and climate change adaptation.

Underlying all this is that policies need to allocate resources-financial and human-for gender responsive interventions at scale and adopt clear accountability mechanisms, such as gender budgeting, to demonstrate their commitment to gender equality as indicated in the SDGs.

In conclusion, we set forth a vision of inclusive development for the HKH complementing, and in the spirit of, the Sustainable Development Goals adopted by the global community in 2015: By 2030, environmental governance processes, policies, and strategies at scale (from local to global) are gender inclusive and cognizant of the mosaic of nested, uniquely diverse, dynamic, and mostly gender-inequitable socio-ecological systems in the HKH.

\section{References}

ADB. (2010). Overview of gender equality and social inclusion in Nepal. Manila: Asian Development Bank.

Adhikary, M. (1995). Women graduates in agriculture and forestry development in Nepal (No. REP-7905. CIMMYT).

Agarwal, B. (1997). Environmental action, gender equity and women's participation. Development and Change, 28(1), 1-44.

Agarwal, B. (2000). Conceptualising environmental collective action: Why gender matters. Cambridge Journal of Economics, 24(3), 283 310 .
Agarwal, B. (2009). Gender and forest conservation: The impact of women's participation in community forest governance. Ecological Economics, 68(11), 2785-2799.

Agarwal, B. (2010). The impact of women in Nepal's community forestry management. Gender perspectives in mountain development. In Sustainable Mountain Development, No. 57, ICIMOD, Summer 2010 (pp. 26-29).

Agrawal, A., Britt, C., \& Kanel, K. (1999). Decentralization in Nepal: A comparative analysis. A report on the participatory district development program. ICS Press Institute for Contemporary Studies.

Akçar, S. (2001). Grassroots women's collectives-Roles in post-disaster effort: Potential for sustainable partnership and good governance (lessons Learned from the Marmara Earthquake in Turkey). United Nations Division for the Advancement of Women.

Alston, M., Whittenbury, K., Haynes, A., \& Godden, N. (2014, December). Are climate challenges reinforcing child and forced marriage and dowry as adaptation strategies in the context of Bangladesh? In Women's Studies International Forum (Vol. 47, pp. 137-144). Pergamon.

Arora-Jonsson, S. (2014, December). Forty years of gender research and environmental policy: Where do we stand? In Women's Studies International Forum (Vol. 47, pp. 295-308). Pergamon.

Atkinson, H. G., \& Bruce, J. (2015). Adolescent girls, human rights and the expanding climate emergency. Annals of Global Health, 81(3), $323-330$

Baden, S., Green, C., Goetz, A. M., \& Guhathakurta, M. (1994). Background report on gender issues in Bangladesh (Vol. 26). University of Sussex. IDS.

Bari, F. (1998). Gender, disaster, and empowerment: A case study from Pakistan (pp. 1-8). The gendered terrain of disaster: Through women's eyes.

Barua, A., Katyaini, S., Mili, B., \& Gooch, P. (2014). Climate change and poverty: Building resilience of rural mountain communities in South Sikkim, Eastern Himalaya, India. Regional Environmental Change, 14(1), 267-280.

Bastola, A., Hynie, M., \& Poudel, S. (2015). Gender and Ethnic Practices: Can gender based practices in ethnic groups illustrate the impacts of climate change? In World Symposium on Climate Change Adaptation, 2-4 September 2015, Manchester. Grantham Research Institute (GRI) (2015). Myanmar. http://www.lse.ac.uk/GranthamInstitute/ legislation/countries/myanmar/. Accessed 26 April 2016.

Bern, C., Sniezek, J., Mathbor, G. M., Siddiqi, M. S., Ronsmans, C., Chowdhury, A. M. et al. (1993). Risk factors for mortality in the Bangladesh cyclone of 1991. Bulletin of the World Health Organization, 71(1), 73.

Bettini, G., \& Gioli, G. (2015). Waltz with development: insights on the developmentalization of climate-induced migration. Migration and Development, 5(2), 171-189.

Bhattarai, B., Beilin, R., \& Ford, R. (2015). Gender, agrobiodiversity, and climate change: A study of adaptation practices in the Nepal Himalayas. World Development, 70, 122-132.

Bose, A. (2000). Demography of Himalayan villages: Missing men and lonely women. Economic and Political Weekly, 2361-2363.

Brockington, D. (2012). A radically conservative vision? The challenge of UNEP's towards a green economy. Development and Change, 43 (1), 409-422.

Brody, A., Demetriades, J., \& Esplen, E. (2008). Gender and climate change: Mapping the linkages, a scoping study on knowledge and gaps. BRIDGE, Institute of Development Studies, University of Sussex.

Buchy, M., \& Rai, B. (2008). Do women-only approaches to natural resource management help women? The case of community forestry in Nepal. Gender and natural resource management: Livelihoods, mobility and interventions (pp. 127-147). 
Buchy, M., \& Subba, S. (2003). Why is community forestry a social-and gender-blind technology? The case of Nepal. Gender, Technology and Development, 7(3), 313-332.

Bullard, N., \& Müller, T. (2012). Beyond the 'Green Economy': System change, not climate change? Development, 55(1), 54-62.

Bushley, B. (2002). Users perceptions of the impacts of community forestry on community development in Nepal's western Terai region. Care Nepal.

Canada, C. A. R. E. (2010). Cyclone Nargis: Myanmar two years later. Ottawa: CARE Canada.

Carvajal-Escobar, Y., Quintero-Angel, M., \& Garcia-Vargas, M. (2008). Women's role in adapting to climate change and variability. Advances in Geosciences, 14, 277-280.

Cash, D., Adger, W. N., Berkes, F., Garden, P., Lebel, L., Olsson, P., et al. (2006). Scale and cross-scale dynamics: Governance and information in a multilevel world. Ecology and Society, 11(2).

Chhetri, G. (2001). A social and cultural perspective of women and community forestry in Nepal. Contributions to Nepalese Studies, 28 (1), 53-72.

Chowdhury, A. M. R., Bhuyia, A. U., Choudhury, A. Y., \& Sen, R. (1993). The Bangladesh cyclone of 1991: Why so many people died. Disasters, 17(4), 291-304. climdev15.pdf. Accessed 6 June 2017

D'Cunha, J. (1997). Engendering disaster preparedness and management. Asian Disaster Management News, 3(3), 2-5.

Dankelman, I. E. M. (2008). Gender, climate change and human security: Lessons from Bangladesh, Ghana and Senegal.

Das, N. (2011). Can gender-sensitive forestry programmes increase women's income? Lessons from a forest fringe community in an Indian province. Rural Society, 20(2), 160-173.

Dasgupta, S., Huq, M., Khan, Z. H., Ahmed, M. M. Z., Mukherjee, N., Khan, M. F., et al. (2010). Vulnerability of Bangladesh to cyclones in a changing climate: Potential damages and adaptation cost.

DFID/WB. (2006). Unequal citizens. Gender, caste and ethnic exclusion in Nepal. Summary. Kathmandu, Nepal: Department for International Development (DFID) and World Bank (WB).

Dhimal, M. L. (2015). Gender differentiated health impacts of environmental and climate change in Nepal. In S. Pradhananga, J. Panthi, \& D. Bhattarai (Eds.), Proceedings of International Conference on Climate Change Innovation and Resilience for Sustainable Livelihood (pp. 96-100), 12-14 January 2015, Kathmandu, Nepal. Kathmandu: Small Earth Nepal. https:// smallearthnepal.files.wordpress.com/2014/06/proceeding.pdf.

Enarson, E. (1999). Women and housing issues in two US disasters: Case studies from Hurricane Andrew and the Red River Valley flood. International Journal of Mass Emergencies and Disasters, 17 (1), 39-63.

Eriksson, M., Fang, J., \& Dekens, J. (2008). How does climate change affect human health in the Hindu Kush-Himalaya region. Regional Health Forum, 12(1), 11-15.

Fairhead, J., Leach, M., \& Scoones, I. (2012). Green Grabbing: A new appropriation of nature? Journal of Peasant Studies, 39(2), 237 261.

Fordham, M. (2001) Challenging boundaries: A gender perspective on early warning in disaster and environmental management. United Nations, Division for the Advancement of Women (DAW), International Strategy for Disaster Reduction (ISDR), Expert group meeting on "Environmental management and the mitigation of natural disasters: A gender perspective", 6-9 November 2001, Ankara, Turkey. https://www.unisdr.org/files/8264_ EP52001Oct261.pdf.

Forsyth, T. (2001). Critical realism and political ecology. In A. Stainer \& G. Lopez (Eds.), (2001) After postmodernism: Critical realism? (pp. 146-154). London: Athlone Press.
Fukuda-Parr, S. (2016). From the millennium development goals to the sustainable development goals: Shifts in purpose, concept, and politics of global goal setting for development. Gender \& Development, 24(1), 43-52. https://doi.org/10.1080/13552074.2016. 1145895.

Gauld, R. (2000). Maintaining centralized control in community-based forestry: Policy construction in the Philippines. Development and Change, 31(1), 229-254.

Gautam, S. R. (2006). Incorporating groundwater irrigation: Technology dynamics and conjunctive water management in the Nepal Terai.

GDMA (Gilgit-Baltistan Disaster Management Authority). (2015). Gilgit Baltistan's (GB) Contingency Plan for Floods.

Goh, A. H. (2012). A literature review of the gender-differentiated impacts of climate change on women's and men's assets and well-being in developing countries. Washington, DC: International Food Policy Research Institute.

Golam Rabbani, M. D., Atiq Rahman, A., \& Mainuddin, K. (2009). Women's vulnerability to water-related hazards: Comparing three areas affected by climate change in Bangladesh. Waterlines, 28(3), 235-249.

GoN. (2014). Labour migration for employment: A status report for Nepal: 2013/2014, Ministry of Labour and Employment, Department of Foreign Employment, Government of Nepal.

Gupta, N. (2007). Indian women in doctoral education in science and engineering a study of informal milieu at the reputed Indian Institutes of Technology. Science, Technology and Human Values, 32(5), 507-533.

Gupta, S., \& Agarwal, B. (2013). Gender and green governance: The political economy of women's presence within and beyond community forestry.

Gupta, S. P., Bhattarai, H. K., \& Sah, R. (2011). Exclusion in community forestry of Nepal. A term paper on exclusion in community forestry of Nepal, Kathmandu University, Nepal.

Gurung, J. D. (1998). Mountain women of the Hindu Kush-Himalayas: The hidden perspective.

Gurung, J. D. (1999). Searching for women's voices in the Hindu Kush-Himalayas. International Centre for Integrated Mountain Development (ICIMOD).

Gurung, D. D., \& Bisht, S. (2014). Women's empowerment at the frontline of adaptation: emerging issues, adaptive practices, and priorities in Nepal. ICIMOD Working Paper, (2014/3).

Gyawali, D., \& Thompson, M. (2016). Restoring Development Dharma with Toad's Eye Science? In IDS Bulletin- 'States, Markets and Society -New Relationships for a New Development Era' (Vol. 47, No. 2A November 2016, pp. 1979-1989). https://opendocs.ids.ac. uk/opendocs/bitstream/handle/123456789/12691/IDSB472A_10. 190881968-2016.192.pdf?sequence=1\&isAllowed=y. Accessed 31 Sept. 2017.

Hamid and Afzal. (November, 2013). Gender, water and climate change: The case of Pakistan.

Hanson, A. M. S. (2015). Shoes in the seaweed and bottles on the beach: Global garbage and women's oral histories of socioenvironmental change in coastal Yucatan. In S. Buechler \& A.-M. Hanson (Eds.), A political ecology of women, water and global environmental change (pp. 165-184).

Harcourt, W., \& Nelson, I. L. (Eds.). (2015). Practising feminist political ecologies: Moving beyond the 'green Economy'. Zed Books.

Harding, S. (2008). Sciences from below: Feminisms, postcolonialities, and modernities. Duke University Press.

Hillenbrand, E., Lakzadeh, P., Sokhoin, L., Talukder, Z., Green, T., \& McLean, J. (2014). Using the social relations approach to capture complexity in women's empowerment: Using gender analysis in the 
Fish on Farms project in Cambodia. Gender \& Development, 22(2), 351-368.

HMGN. (1993). Forest Act 2049, Ministry of Law and Justice, His Majesty's Government of Nepal. http://www.wedo.org/wp-content/ uploads/hsn-studyfinal-may-20-2008.pdf.

IFRC. (2007). World disaster report. Focus on discrimination. http:// www.ifrc.org/Global/Publications/disasters/WDR/WDR2007English.pdf.

IFRC. (2015). Epidemic preparedness in Myanmar. https://www. preparecenter.org/sites/default/files/epdemic_preparedness_in_ myanmar.pdf.

Jasanoff, S. (2010). A new climate for society. Theory, Culture \& Society, 27(2-3), 233-253.

Jodha, N. S. (2007). Mountain commons: Changing space and status at community levels in the Himalayas. Journal of Mountain Science, 4 (2), 124-135.

Joshi, D. (2014). Feminist solidarity? Women's engagement in politics and the implications for water management in the Darjeeling Himalaya. Mountain Research and Development, 34(3), 243-254.

Kabeer, N. (1994). Reversed realities: Gender hierarchies in development thought. Verso.

Kabeer, N., \& Subrahmanian, R. (1996). Institutions, relations and outcomes: Framework and tools for gender-aware planning. Brighton, UK: Institute of Development Studies.

Kanel, K. R. (2007). Economic impacts of forest policy changes: A perspective from Nepal. The Initiation, 1, 36-42.

Karki, M., Sharma S., Mahat, T., Aksha, S., \& Tuladhar, A. (2011). From Rio 1992 to 2012 and beyond: Sustainable mountain development Hindu Kush Himalaya (HKH) region. Draft for Discussion. Regional Assessment Report for Rio+20: Hindu Kush Himalaya and SE Asia Pacific Mountains. Kathmandu: ICIMOD.

Khan, M., \& Kumar, U. (2010). Water security in Peri-urban South Asia. Adapting to climate change and urbanization, scoping study report, IWFM, BUET, Khulna. http://saciwaters.org/periurban/ Scoping_Study_Report_Khulna.pdf. Accessed 30 Sept. 2017.

Khan, A., Mojumder, S. K., Kovats, S., \& Vineis, P. (2008). Saline contamination of drinking water in Bangladesh. The Lancet, 371 (9610), 385.

Khan, A. E., Scheelbeek, P. F. D., Shilpi, A. B., Chan, Q., Mojumder, S. K., Rahman, A., et al. (2014). Salinity in drinking water and the risk of (pre) eclampsia and gestational hypertension in coastal Bangladesh: a case-control study. PLoS One, 9(9), e108715.

Khan, M. S. A., Shahjahan Mondal, M., Rahman, R., Huq, H., Datta, D. K., Kumar, U., et al. (2016). Urban burden on Peri-urban areas: Shared use of a river in a coastal city vulnerable to climate change. In V. Narain \& P. Anjal (Eds.), Water security in Peri-urban South Asia: Adapting to climate change and urbanization (pp. 286-296). New Delhi, India: Oxford University Press.

Kosoy, N., Brown, P. G., Bosselmann, K., Duraiappah, A., Mackey, B., Martinez-Alier, J., et al. (2012). Pillars for a flourishing Earth: Planetary boundaries, economic growth delusion and green economy. Current Opinion in Environmental Sustainability, 4(1), 7479.

Kulkarni, S., Bhat, S., Majumdar, S., \& Goodrich, C. G. (2009). Situational analysis of women water professionals in South Asia.

Lahiri-Dutt, K. (2014). Experiencing and coping with change: Women-headed farming households in the Eastern Gangetic Plains. Australian Centre for International Agricultural Research.

Lama, A., \& Buchy, M. (2002). Gender, class, caste and participation: The case of community forestry in Nepal. Bulletin (Centre for Women's Development Studies), 9(1), 27-41.

Lauren Khan, A. (2012). Chapter 9 creative adaptation: Bangladesh's resilience to flooding in a changing climate. In Climate Change
Modeling For Local Adaptation In The Hindu Kush-Himalayan Region (pp. 159-175). Emerald Group Publishing Limited.

Laurie, N. (2005). Establishing development orthodoxy: Negotiating masculinities in the water sector. Development and Change, 36(3), $527-549$

Leach, M., Joekes, S., \& Green, C. (1995). A predominant set of perspectives highlights, 26(1).

LEAD Pakistan. (March, 2015). Early warning system and disaster risk information, leadership for environment \& development (LEAD) Pakistan.

Leduc, B. (2009). Gender and climate change in the Himalayas, background paper for e-discussion. In Climate Change in the Himalayas: The Gender Perspective, 5-25 October, ICIMOD. Kathmandu: ICIMOD and Asia Pacific Mountain Network (APMN).

Leduc, B. (2010). Adaptation to climate change-why gender makes a difference? Adaptation to climate change-why gender makes a difference? (57), 8-11.

Leduc, B., \& Shrestha, A. (2008). Gender and climate change in the Hindu Kush-Himalayas: Nepal case study. Kathmandu, Nepal: International Centre for Integrated Mountain Development (ICIMOD).

Leduc, B., Shrestha, A., \& Bhattarai, B. (2008). Gender and climate change in the Hindu Kush Himalayas of Nepal. International Centre for Integrated Mountain Development (ICIMOD) for WEDO, 8.

Liebrand, J. (2010). Masculinities: A scale challenge in irrigation governance in Nepal. In Dynamics of farmer managed irrigation systems: Socio-institutional, economic and technical contexts (pp. 53-72).

Liebrand, J. (2014). Masculinities among irrigation engineers and water professionals in Nepal. Ph.D. thesis, Wageningen University, Wageningen, NL. ISBN: 978-94-6257-141-9.

MacGregor, S. (2010). 'Gender and climate change': From impacts to discourses. Journal of the Indian Ocean Region, 6(2), 223-238.

Maharjan, M. R. (1998). The flow and distribution of costs and benefits in the Chuliban community forest, Dhankuta District, Nepal. Rural Development Forestry Network, 23, 1-12.

Malla, Y. B., Neupane, H. R., \& Branney, P. J. (2003). Why aren't poor people benefiting more from community forestry. Journal of forest and livelihood, 3(1), 78-92.

Mallick, D., Golam Jilani, K., \& Akand, E. S. (2016). Vulnerability of women and poor to climate change; gender responsive adaptation in Bangladesh. Bangladesh Centre for Advanced Studies and Christian Aid, Dhala, Bangladesh, July.

Maraseni, T. N. (2012). Climate change, poverty and livelihoods: Adaptation practices by rural mountain communities in Nepal. Environmental Science \& Policy, 21, 24-34.

Massey, D. S., Axinn, W. G., \& Ghimire, D. J. (2010). Environmental change and out-migration: Evidence from Nepal. Population and Environment, 32(2-3), 109-136.

Mehta, M. (1996). Our lives are no different from that of our buffaloes: Agricultural change and gendered spaces in a central Himalayan valley. Feminist political ecology: Global issues and local experiences (pp. 180-210).

Mehta, M. (2007). Gender matters: Lessons for disaster risk reduction in South Asia. International Centre for Integrated Mountain Development (ICIMOD).

Moitra, A., \& Kumar, A. (2016). Hill women's voices and community communication about climate change: The case of Henvalvani Community Radio in India. The praxis of social inequality in India: A global perspective (pp. 137-159).

Molyneux, M. (2007). 18| The chimera of success: Gender ennui and the changed international policy environment. Feminisms in Development: Contradictions, Contestations and Challenges, 9, 227. 
Morrow, B. H., \& Phillips, B. (1999). What's gender "Got to do with it"? International Journal of Mass Emergencies and Disasters, 17 (1), 5-11.

Moser, C. (2012). Gender planning and development: Theory, practice and training. Routledge.

Mukhopadhyay, M. (2004). Mainstreaming gender or "streaming" gender away: Feminists marooned in the development business. IDS Bulletin, 35(4), 95-103.

Mustafa, D., Gioli, G., Qazi, S., Waraich, R., Rehman, A., \& Zahoor, R. (2015). Gendering flood early warning systems: The case of Pakistan. Environmental Hazards, 14(4), 312-328.

Nair, S. (2012). Women in Indian engineering: A preliminary analysis of data from the graduate level engineering education field in Kerala and Rajasthan.

Nellemann, C., Verma, R., Hislop, L. (Eds.), (2011). Women at the frontline of climate change: Gender risks and hopes. A rapid response assessment. United Nations Environment Programme, GRID-Arendal.

Nelson, V., Meadows, K., Cannon, T., Morton, J., \& Martin, A. (2002). Uncertain predictions, invisible impacts, and the need to mainstream gender in climate change adaptations. Gender \& Development, 10 (2), 51-59.

Neumayer, E., \& Plümper, T. (2007). The gendered nature of natural disasters: The impact of catastrophic events on the gender gap in life expectancy, 1981-2002. Annals of the Association of American Geographers, 97(3), 551-566.

Neupane, H. (2003). Contested impact of community forestry on equity: Some evidence from Nepal. Journal of Forest and Livelihood, 2(2), $55-61$.

Nibanupudi, H. K., \& Khadka, M. (2015). Gender and disaster resilience in Hindu Kush Himalayan Region. In H. K. Nibanupudi \& R. Shaw (Eds.), Mountain hazards and disaster risk reduction, disaster risk reduction (pp. 233-249). https://doi.org/10.1007/978-4431-55242-0_13.

Nightingale, A. J. (2002). Participating or just sitting in? The dynamics of gender and caste in community forestry. Journal of forest and livelihood, $2,1$.

ODI (Overseas Development Institute). 2007. Gender fatigue: What can we do to overcome it? (7 March 2007).

Ogra, M. V., \& Badola, R. (2015). Gender and climate change in the Indian Himalayas: Global threats, local vulnerabilities, and livelihood diversification at the Nanda Devi Biosphere Reserve. Earth System Dynamics, 6(2).

Ongsakul, R., Resurreccion, B., \& Sajor, E. (2012). Normalizing masculinities in water bureaucracy in Thailand. International Journal of Public Administration, 35(9), 577-586.

Parajuli, R., Pokharel, R. K., \& Lamichhane, D. (2010). Social discrimination in community forestry: Socio-economic and gender perspectives. Banko Janakari, 20(2), 26-33.

Parikh, J. (2007). Gender and climate change framework for analysis, policy \& action.

Parikh, P. P., \& Sukhatme, S. P. (2004). Women engineers in India. Economic and Political Weekly, 193-201.

Paudel, G. (2012). Forest size, income status and inequality. Doctoral dissertation, Tribhuvan University.

Paudel, D., \& Paudel, G. (2013). Corpo-bureaucratizing community forest: Commercialization and increased financial transaction in community forestry user groups in Nepal. Journal of Forest and Livelihood, 9(1), 1-15.

Paudyal, B. R. (2008). Agrarian structures and distributive outcomes: A study of community forestry in Nepal. Doctoral dissertation, International Institute of Social Studies of Erasmus University (ISS).

PDMA/KP. (2015). Report on Torrential Rains and Mini Cyclone in Peshawar Division (April 26). Provincial Disaster Management
Authority Relief, Rehabilitation \& Settlement Department, Government of Khyber Pakhtunkhwa.

Pender, E. (2009). Opportunities for coordination: Protection, women's protection and gender based violence. GenCap.

Prakash, A. (2016). Towards Peri-urban water security- implications for adaptive capacity, public policy, and future research and action. In V. Narain \& P. Anjal (Eds.), Water security in Peri-urban South Asia: Adapting to climate change and urbanization (pp. 286-296). New Delhi, India: Oxford University Press.

Rai, B., \& Buchy, M. (2004, August). Institutional exclusion of women in community forestry: Is women-only strategy a right answer. In Twenty-five years of community forestry: Proceedings of the Fourth National Workshop on Community Forestry (pp. 4-6).

Rai, S., Shah, N., \& Avaz, A. (2007). Achieving gender equality in public offices in Pakistan.

Rocheleau, D., Thomas-Slayter, B., \& Wangari, E. (1996). Feminist political ecology: Global issues and local experience. Routledge.

Roehr, U. (2007). Gender, climate change and adaptation. Introduction to the gender dimensions. In Both Ends Briefing Paper Series.

Seeley, J. (1996). Women, Men and Roles in Forestry. Banko Janakari, 6(1), 39.

Shah, S. A. (2012). Gender and building homes in disaster in Sindh, Pakistan. Gender \& Development, 20(2), 249-264.

Shah, S. A., \& Memon, N. (2012). Entering male domain and challenging stereotypes. In A. Prakash, G. C. Goodrich, \& S. Singh (Eds.), Informing Water Policies: Case Studies from South Asia. Rutledge, New Delhi.

Sharmin, Z., \& Islam, M. S. (2013). Consequences of climate change and gender vulnerability: Bangladesh perspective.

Shrestha, P., Lord, A., Mukherji, A., Shrestha, R. K., Yadav, L., \& Rai, N. (2016). Benefit sharing and sustainable hydropower: Lessons from Nepal. ICIMOD Research Report 2016/2. Kathmandu: Nepal.

Shukla, A., \& Sharma, K. R. (1997). Participatory irrigation management in Nepal: A monograph on evolution, processes and performance.

Sidh, S. N., \& Basu, S. (2011). Women's contribution to household food and economic security: A study in the Garhwal Himalayas, India. Mountain Research and Development, 31(2), 102-111.

Singh, N., \& Singh, O. P. (2015). Climate change, water and gender: Impact and adaptation in North-Eastern Hills of India. International Social Work, 58(3), 375-384.

Singh, S. P., Bassignana-Khadka, I., Karky, B. S., \& Sharma, E. (2011). Climate change in the Hindu Kush-Himalayas: The state of current knowledge. International Centre for Integrated Mountain Development (ICIMOD).

Singh, M., Liebrand, J., \& Joshi, D. (2014). Cultivating "success" and "failure" in policy: Participatory irrigation management in Nepal. Development in Practice, 24(2), 155-173.

Skinner, E. (2011). Gender and climate change: Overview report. Bridge.

Sogani, R. (2013). Climate change: A Himalayan perspective 'Local Knowledge-The Way Forward'. In Research, action and policy: Addressing the gendered impacts of climate change (pp. 265-275). The Netherlands: Springer.

Song, Y., \& Vernooy, R. (2010). Seeds of empowerment: action research in the context of the feminization of agriculture in southwest China. Gender, Technology and Development, 14(1), $25-44$.

Song, Y., \& Zhang, Y. (2015). SIFOR China project base-line study report.

Song, Y., Qi, G., Zhang, Y., \& Vernooy, R. (2014). Farmer cooperatives in China: Diverse pathways to sustainable rural development. International Journal of Agricultural Sustainability, 12(2), 95-108. 
Song, Y., Zhang, Y., Song, X., \& Vernooy, R. (2016). Access and benefit sharing in participatory plant breeding in Southwest China. Farming matters. Special Issue, Access and benefit sharing of genetic resources (pp. 18-23).

SPDC. (2015). Gender and social vulnerability to climate change; A study of disaster prone areas in Sindh. Social Policy and Development Centre (SPDC).

Staddon, S. C., Nightingale, A., \& Shrestha, S. K. (2015). Exploring participation in ecological monitoring in Nepal's community forests. Environmental Conservation, 42(03), 268-277.

Stone, S. (2011). Towards a green economy: Pathways to sustainable development and poverty eradication-A synthesis for policy makers. Environment, 1-34. http://doi.org/10.1063/1.3159605.

Sugden, F., Silva, S. D., Clement, F., Maskey-Amatya, N., Ramesh, V., Philip, A., et al. (2014). A framework to understand gender and structural vulnerability to climate change in the Ganges River Basin: Lessons from Bangladesh, India and Nepal. IWMI Working Paper, (159).

Sultana, F. (2010). Living in hazardous waterscapes: Gendered vulnerabilities and experiences of floods and disasters. Environmental Hazards, 9(1), 43-53.

Taylor, M. (2014). The political ecology of climate change adaptation: Livelihoods, agrarian change and the conflicts of development. Routledge.

Tetlay, M., \& Raza, A. (1998). From small farmer development to sustainable livelihood: A case study on the Evolution of AKRSP in Northern Pakistan. Aga han Khan Rural support program, Gilgit, Northern Areas. Pakistan.

Tschakert, P. (2012). From impacts to embodied experiences: Tracing political ecology in climate change research. Geografisk Tidsskrift-Danish Journal of Geography, 112(2), 144-158.

Tulachan, P. M. (2001). Mountain agriculture in the Hindu KushHimalaya: A regional comparative analysis. Mountain Research and Development, 21(3), 260-267.

Twigg, J. (2004). Disaster risk reduction: Mitigation and preparedness in development and emergency programming. Humanitarian Practice Network, Overseas Development Institute.

Tyagi, N., \& Das, S. (2017). Gender mainstreaming in forest governance: Analysing 25 years of research and policy in South Asia. International Forestry Review, 19(2), 34-44.

Udas, P. B., \& Zwarteveen, M. Z. (2010). Can water professionals meet gender goals? A case study of the Department of Irrigation in Nepal. Gender \& Development, 18(1), 87-97.

UNDP. (1995). Human Development Report 1995. New York: Oxford University Press.
UNDP. (2010). Gender, climate change and community-based adaptation. New York: UNDP.

UNEP. (1997). Global Environmental Outlook. Oxford, UK: United Nations Environmental Programme and Oxford University Press.

UNEP. (2009). Learning from Cyclone Nargis: Investing in the environment for livelihoods and disaster risk reduction: A case study. Nairobi, Kenya: United Nations Environment Programme (UNEP).

UNEP. (2012). Myanmar's national adaptation programme of action (NAPA) to climate change. http://unfccc.int/resource/docs/napa/ mmr01.pdf. Accessed 26 April 2016.

UN-HABITAT. (2007). Global report on human settlement 2007. Enhancing Urban Safety and Security. EarthScan. London. Sterling VA.

UNIFEM. (2010). Pakistan floods 2010-Preliminary rapid gender assessment of Pakistan's flood crisis (pp. 1-32). UNIFEM, United Nations Development Fund for Women.

Uprety, D. R., Gurung, A., Bista, R., Karki, R., \& Bhandari, K. (2012). Community forestry in Nepal: A scenario of exclusiveness and its implications. Frontiers in science, 2(3), 41-46.

Vincent, K., Wnajiru, L., Aubry, A., Mershon, A., Nyandiga, C., Cull, T., et al. (2010). Gender, climate change and community-based adaptation: A guidebook for designing and implementing gender sensitive community-based adaptation programmes and projects.

WEDO. (2008). Gender, climate change, and human security: Lessons from Bangladesh, Ghana, and Senegal.

Winrock. (2002). Emerging issues in community forestry in Nepal. Kathmandu: Winrock International, Nepal.

Women's Protection Technical Working Group. (2010). Women's protection assessments: post cyclone Nargis, Myanmar. http:// reliefweb.int/sites/reliefweb.int/files/resources/ F6CAA5ECD57BC6054925776100202353-Full_Report.pdf. Accessed 27 April 2016.

World Bank. (2010). The social dimensions of adaptation to climate change in Bangladesh. Discussion paper, No. 12. Washington, DC: World Bank.

Yadav, B. D., Bigsby, H. R., \& MacDonald, I. A. (2008). Who are controlling community forestry user groups in Nepal? Scrutiny of elite theory.

Zwarteveen, M. Z. (2006). Wedlock or deadlock? Feminists' attempts to engage irrigation engineers. Ponsen \& Looijen.

Zwarteveen, M. Z. (2008). Men, masculinities and water powers in irrigation. Water Alternatives, 1(1), 111-130.

Zwarteveen, M. (2011). Questioning masculinities in water. Economic and Political Weekly, 40-48.
Open Access This chapter is licensed under the terms of the Creative Commons Attribution 4.0 International License (http:// creativecommons.org/licenses/by/4.0/), which permits use, sharing, adaptation, distribution and reproduction in any medium or format, as long as you give appropriate credit to the original author(s) and the source, provide a link to the Creative Commons license and indicate if changes were made.
The images or other third party material in this chapter are included in the chapter's Creative Commons license, unless indicated otherwise in a credit line to the material. If material is not included in the chapter's Creative Commons license and your intended use is not permitted by statutory regulation or exceeds the permitted use, you will need to obtain permission directly from the copyright holder. 